\title{
Present Tectonic Setting and Spatio-Temporal Distribution of Seismicity in the Apennine Belt
}

\author{
Enzo Mantovani', Marcello Viti'1, Daniele Babbucci'1, Caterina Tamburelli1, Nicola Cenni' \\ Massimo Baglione ${ }^{3}$, Vittorio D'Intinosante ${ }^{3}$ \\ ${ }^{1}$ Dipartimento di Scienze Fisiche, della Terra e dell'Ambiente, Università degli Studi di Siena, Siena, Italy \\ ${ }^{2}$ Dipartimento di Scienze Biologiche, Geologiche e Ambientali, Università degli Studi di Bologna, Bologna, Italy \\ ${ }^{3}$ Settore Sismica, Regione Toscana, Firenze, Italy \\ Email: marcello.viti@unisi.it
}

Received 26 February 2015; accepted 14 April 2015; published 20 April 2015

Copyright (C) 2015 by authors and Scientific Research Publishing Inc.

This work is licensed under the Creative Commons Attribution International License (CC BY).

http://creativecommons.org/licenses/by/4.0/

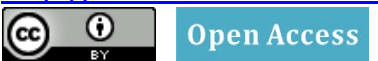

\begin{abstract}
In previous papers, we have argued that a close connection may exist between the discontinuous northward displacement of the Adria plate and the spatio-temporal distribution of major earthquakes in the periAdriatic regions [1]-[3]. In particular, five seismic sequences are tentatively recognized in the post 1400 A.D. seismic history, each characterized by a progressive migration of major shocks along the eastern (Hellenides, Dinarides), western (Apennines) and northern (Eastern Southern Alps) boundaries of Adria. In this work, we describe an attempt at gaining insights into the short-term evolution of the strain field that underlies the migration of seismicity in the Apennine belt. The results of this study suggest that seismicity in the study area is mainly conditioned by the fact that the outer (Adriatic) sector of the Apennine belt, driven by the Adria plate, is moving faster than the inner (Tyrrhenian) belt. This kinematics is consistent with the observed Pleistocene deformation pattern and the velocity field inferred by GPS data. The spatio-temporal distribution of major shocks during the last still ongoing seismic sequence (post 1930) suggests that at present the probability of next major shocks is highest in the Northern Apennines. Within this area, we suggest that seismic hazard is higher in the zones located around the outer sector of the Romagna-Marche-Umbria units (RMU), since that wedge is undergoing an accelerated relative motion with respect to the inner Apennine belt. This hypothesis may also account for the pattern of background seismicity in the Northern Apennines. This last activity might indicate that the Upper Tiber Valley fault system is the most resisted boundary sector of the RMU mobile wedge, implying an higher probability of major earthquakes.
\end{abstract}




\section{Keywords}

\section{Seismotectonics, Seismic Hazard, GPS, Apennines, Mediterranean}

\section{Introduction}

The present knowledge about the large scale geodynamics and tectonic setting in the central Mediterranean area [4]-[11] suggests that the Adriatic plate (Adria hereafter), stressed by the convergence of the confining plates (Africa, Eurasia and Anatolian-Aegean system), tends to move roughly northward (Figure 1). The relative displacement of this plate with respect to the surrounding regions is accommodated by major decoupling earthquakes along the periAdriatic orogenic belts (Hellenides, Dinarides, Eastern Southern Alps and Apennines). Plate motion is very slow during quiescent periods, while it locally accelerates during co-seismic and postseismic phases, in line with the well-known concept of accelerated plate tectonics [12]-[15].

Each strong shock at a periAdriatic boundary zone triggers a perturbation of the strain field, known as postseismic relaxation [16]-[21], that propagating through the plate may significantly increase the probability of shocks at the other boundary sectors of Adria. Once most periAdriatic fault zones have been activated by major decoupling earthquakes, one could expect that the whole Adria plate has accomplished a further step in its northward migration [2] [3]. Hereafter, the set of major periAdriatic shocks that contributed to one of these steps is recalled as seismic sequence. The starting of one sequence at the southern periAdriatic zones may occur during the last development of the previous sequence at the northern boundaries of Adria.

The proposed tectonic setting in the periAdriatic zones and its possible connection with the time pattern of major earthquakes that have occurred since 1400 A.D. are described in the next two sections. In section 4, attention is focused on how the migrations of major earthquakes have developed in the Apennine belt during the periAdriatic seismic sequences cited above.

As last, we argued that the short term implications of the proposed tectonic setting may also influence the spatio-temporal distribution of the minor seismicity recently occurred in the Northern Apennines.

\section{Interaction of the Adria Plate with the Surrounding Belts}

The progressive northward displacement of Adria is mainly accommodated by tectonic activity at the eastern (Northern Hellenides, Dinarides), northern (Eastern Southern Alps) and western (Apennines) boundaries of such plate, involving various strain styles (Figure 1).

Underthrusting of Adriatic lithosphere mainly develops beneath the Northern Hellenides (from the Ionian Islands to Albania) and Southern Dinarides (e.g., [23]-[26]). Seismotectonic activity is highest at the northern Hellenic sector since such zone marks the collision zone between converging blocks (Adria and the Anatolian Aegean system), while at the Southern Dinarides tectonic activity is mainly due to the motion of Adria with respect to the almost fixed Carpatho-Pannonian-Balkan system. The relative motion between the southern Hellenic sector (Peloponnesus wedge), facing the Ionian oceanic lithosphere and the northern Hellenic sector, facing the Adriatic continental domain [4], is mainly accommodated by dextral transpressional at the Cephalonia fault system [27]. The relative motion between the northern part of Adria and the Northern Dinarides is allowed by a dextral transpressional fault system [28]-[31]. The Adriatic lithosphere underthrusts the Alpine edifice at the Eastern Southern Alps [32] [33].

The tectonic context is more complex at the western side of Adria, since the left lateral relative motion of this plate with respect to the Apennine belt has caused a peculiar deformation of the outer sector of that chain [4] [7] [9] [11] [34]. Forced by belt parallel compression, induced by the motion of the Adriatic plate, the eastern sector of the Apennine belt has undergone uplift and NE ward extrusion, at the expense of the adjacent Adriatic domain (Figure 1).

The proposed long term kinematic pattern of the Apennine belt is compatible with the present velocity field inferred from GPS data (Figure 2). The relatively high density of the station network considered for this study [34]-[36] allows a fairly good definition of the belt sector characterized by significantly higher velocities (4 - 6 $\mathrm{mm} / \mathrm{y}$ ) with respect to the inner belt (less than $1.5 \mathrm{~mm} / \mathrm{y}$ ). 


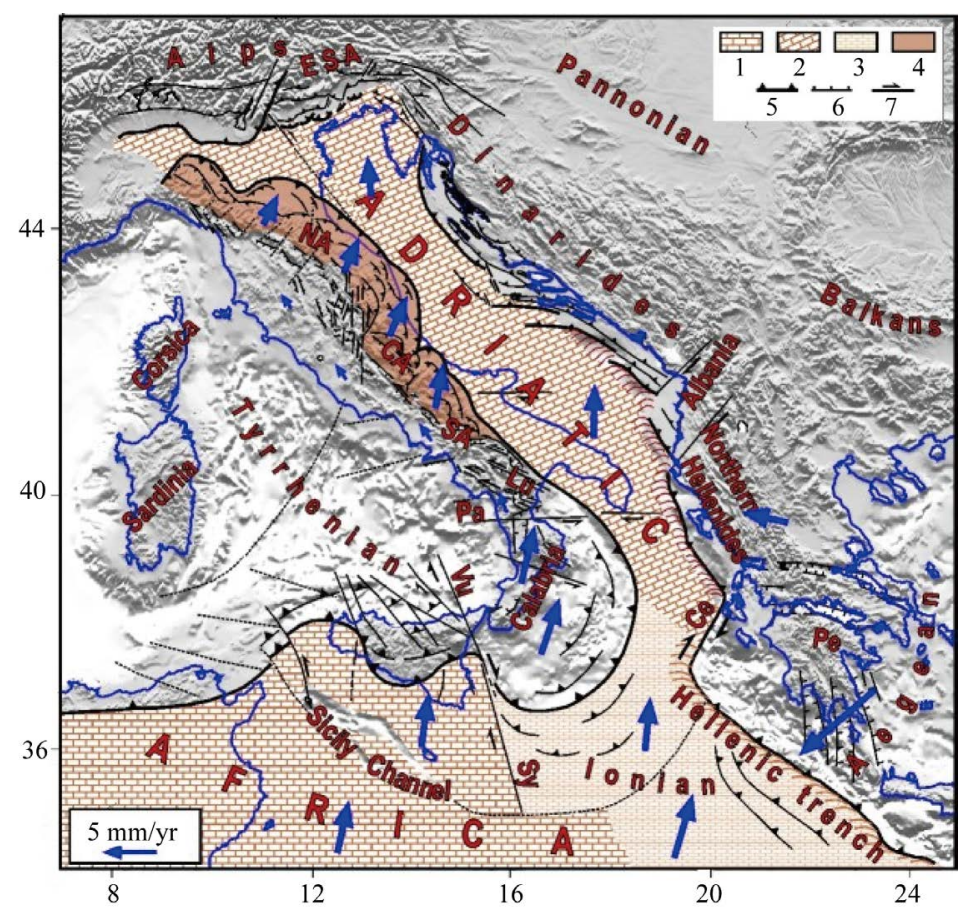

Figure 1. Tectonic/kinematic sketch of the central Mediterranean region (from [1] [4] [6] [7] [9] [11] [22]). 1, 2) African and Adriatic continental domains 3) Ionian oceanic domain 4) Outer sector of the Apennine belt stressed by the Adriatic plate 5, 6, 7) Major compressional, extensional and transcurrent tectonic features. Blue arrows indicate the proposed kinematic pattern with respect to Eurasia ([6] [11]). CA = Central Apennines, $\mathrm{Ce}=$ Cephalonia fault, ESA = Eastern Southern Alps, Lu = Lucanian Apennines, $\mathrm{NA}=$ Northern Apennines, $\mathrm{Pa}=$ Palinuro fault, $\mathrm{Pe}=$ Peloponnesus, $\mathrm{SA}=$ Southern Apennines, $\mathrm{Vu}-\mathrm{Sy}=$ Vulcano-Syracuse fault system.

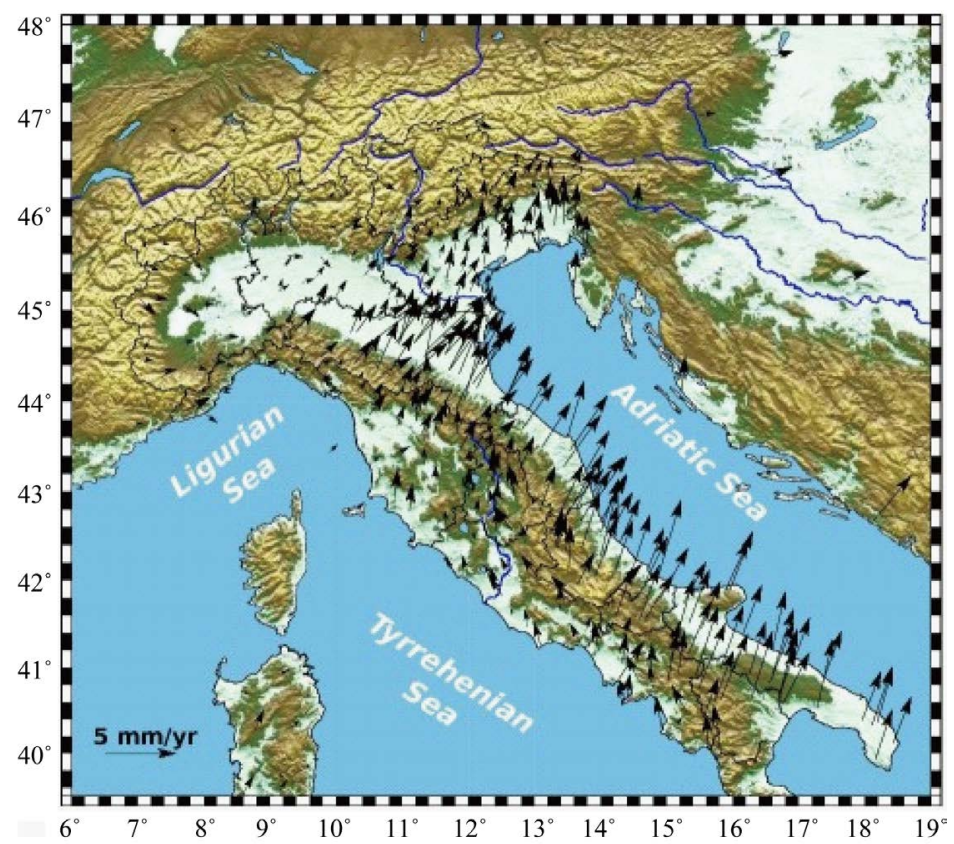

Figure 2. Residual horizontal velocities (black vectors) of the GPS sites with respect to a fixed Eurasian frame (Euler pole at $54.23^{\circ} \mathrm{N}, 98.83^{\circ} \mathrm{W}, \omega=0.257^{\circ} / \mathrm{My}$, [37]). Data and methodology described by [34] [35]. 
The outward extrusion of the Apennine wedges (Figure 1) has caused their separation from the inner, less mobile part of the chain, that has been accommodated by extensional and sinistral transtensional deformation, mainly concentrated in the axial part of the chain [38], where a series of continental intramontane basins has developed in the Quaternary (Figure 3). On the other hand, compressional deformation develops at the outer front of the extruding wedges, where they overthrust the Adriatic domain [39].

The mobile belt is constituted by the Molise-Sannio (MS) wedge in the Southern Apennines, the eastern sector of the Lazio-Abruzzi carbonate platform (ELA) in the Central Apennines, and the Romagna-Marche-Umbria (RMU) and Toscana-Emilia (TE) wedges, in the Northern Apennines. The escaping material only involves the sedimentary cover, decoupled from its crustal basement at seismogenic depth (of the order of $6-10 \mathrm{~km}$ ) by mechanically weak lithological horizons, as evidenced by seismic survey [40] [41].

In the Southern Apennines, the decoupling of the MS wedge from the inner belt is mostly accommodated by extensional/transtensional deformation at the Irpinia, Benevento and Matese fault zones [9] [42] [43]. In the Central Apennines, the relative motion between the ELA platform and the inner belt is accommodated at two major NW-SE sinistral transtensional fault systems (L'Aquila and Fucino, e.g., [7] [9] [38] [44]-[47]). In the Northern Apennines, the divergence between the RMU wedge and the inner belt is accommodated by extensional/transtensional deformation at a series of fault systems, such as, in particular, the Norcia-Colfiorito-Gualdo

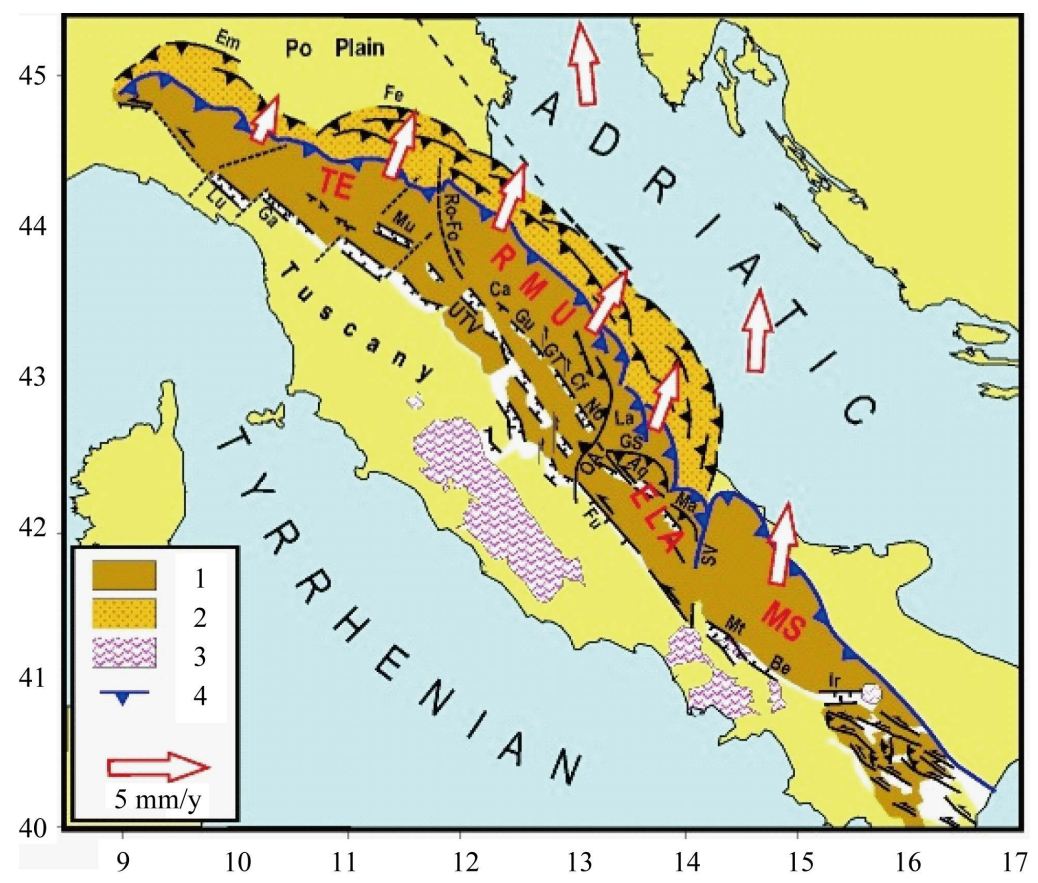

Figure 3. Post-early Pleistocene tectonic/kinematic setting in the Apennine belt (after [34], modified). The outward escape of the wedges located along the eastern Apennine belt (dark brown, ELA = Eastern Lazio-Abruzzi, MS = MoliseSannio, RMU = Romagna-Marche-Umbria, TE = Toscana-Emilia) accommodates the longitudinal shortening driven by the motion of the Adria plate (Figure 1). White arrows indicate the presumed long term average kinematics of Adria and the Apennine wedges. Aq = L'Aquila fault system, Be = Benevento fault system, $\mathrm{Ca}=$ Cagli zone, $\mathrm{Em}=$ Emilia buried folds; $\mathrm{Fe}=$ Ferrara buried folds; $\mathrm{Fu}=$ Fucino fault system, $\mathrm{Ga}=$ Garfagnana trough, $\mathrm{GS}=$ Gran Sasso Arc, Ir = Irpinia fault system, $\mathrm{La}=$ Laga Units, $\mathrm{Lu}=$ Lunigiana trough, $\mathrm{Ma}=$ Maiella, $\mathrm{Mt}$ $=$ Matese fault system, $\mathrm{Mu}=$ Mugello trough, No-Cf-GT-Gu = Norcia-Colfiorito-GualdoTadino-Gubbio fault system, $\mathrm{OA}=$ Olevano-Antrodoco thrust front, Ro-Fo = Supposed fault system in the Romagna Apennines and Forlì zone, tentatively inferred from the alignment of strong historical earthquakes, SV = Sangro-Volturno thrust front, UTV = Upper Tiber Valley fault system. 1) Outer mobile part of the Apennine belt, 2) buried Apennine folds, 3) Quaternary volcanism, 4) Main thrust fronts. 
Tadino-Gubbio (No-Cf-GT-Gu) and the Upper Tiber Valley (UTV) up to the Romagna fault system [38] [48] [49] or/and by the a series of older fault systems located along the western border of the RMU wedge (Figure 3).

Since the belt parallel push exerted by the ELA wedge and transmitted by the RMU wedge also stresses the TE wedge, one may expect to observe effects of this compression along the boundaries of that Apennine sector. However, it must be taken into account that such effects may be significantly attenuated by the fact that shortening is first accommodated by the deformation that develops in the RMU wedge. The residual (not accommodated) stress may then produce effects in the Romagna-Forli decoupling fault system and/or around the outer (Emilia and Ferrara buried folds) and inner (Mugello, Garfagnana and Lunigiana troughs) boundaries of the TE wedge [1]-[3] [34]. In our opinion, the Ro-Fo fault system allows the independent motion between the RMU wedge (mostly parallel to the Adria plate) and the TE wedge, whose mobility encounters much higher resistance.

Insights into the possible connection between the geodetic kinematic field and the distribution of seismic activity in the study area are provided by Figure 4(a), which shows that the narrow zone lying between the mobile RMU wedge and the inner belt, corresponding to the No-Cf-GT-Gu extensional fault system (Figure 3), has been the site of the strongest historical earthquakes.

The relative motion between the Molise-Sannio wedge and the Calabria Arc is accommodated by the system of NW-SE sinistral strike-slip faults recognized in the Lucanian Apennines [9] [50]-[52]. To the South, this system is confined by the Palinuro fault [9] [53]-[55].

\section{Spatio-Temporal Distribution of Major Earthquakes in the PeriAdriatic Zones}

Taking into account the kinematic/tectonic context described above and the fact that each seismic activation of a periAdriatic zone may influence the probability of strong shocks in the next sectors [1] [22] [56]-[59], one could expect to observe regularities in the spatio-temporal distribution of seismicity along the periAdriatic zones. This hypothesis is consistent with the time pattern of major earthquakes that occurred at the main periAdriatic zones since 1400 A.D. (Figure 5). Such patterns are given in the form of annual and decennial sums of seismic slips, computed by the relation between average fault slip and magnitude suggested by [60], since we think that such

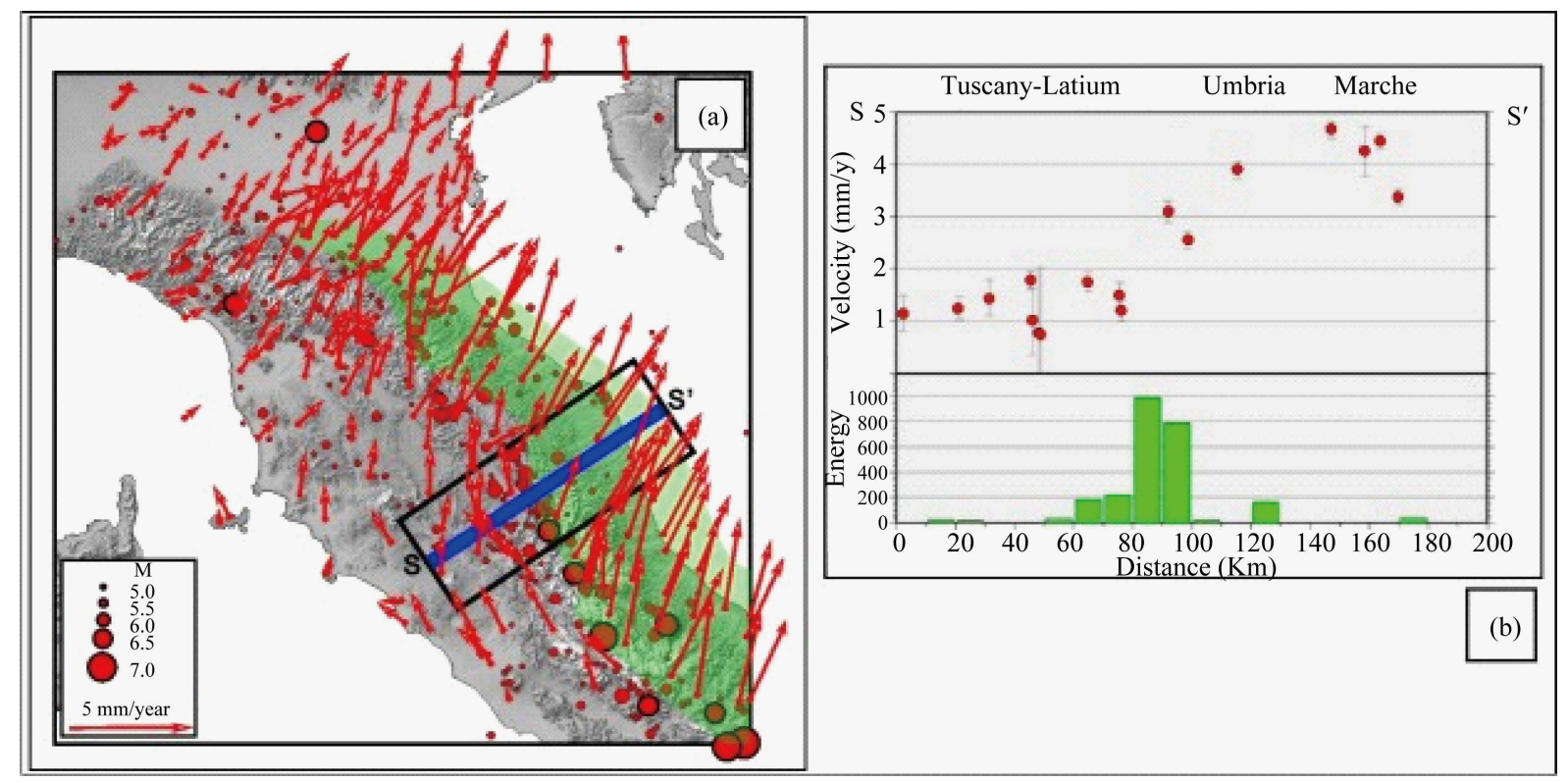

Figure 4. (a) Residual geodetic velocity field with respect to Eurasia [2] [36]. The zone where GPS velocities are higher than $3.5 \mathrm{~mm} / \mathrm{y}$ is evidenced by green. Red circles indicate the epicentres of major earthquakes occurred since 1000 A.D.; M is the magnitude. (b) Top: horizontal velocities (component parallel to the section S-S') of the GPS sites lying within the box in (a). Bottom: total seismic energy $\left(\times 10^{19} \mathrm{erg}\right)$ released in the zone considered (box) since 1000 A.D., computed by the standard relation $\mathrm{E}=10^{(11.8+1.5 \mathrm{M})}$. The location of maximum energy fairly well corresponds to the No-Cf-GT-Gu fault system (Figure 3). 

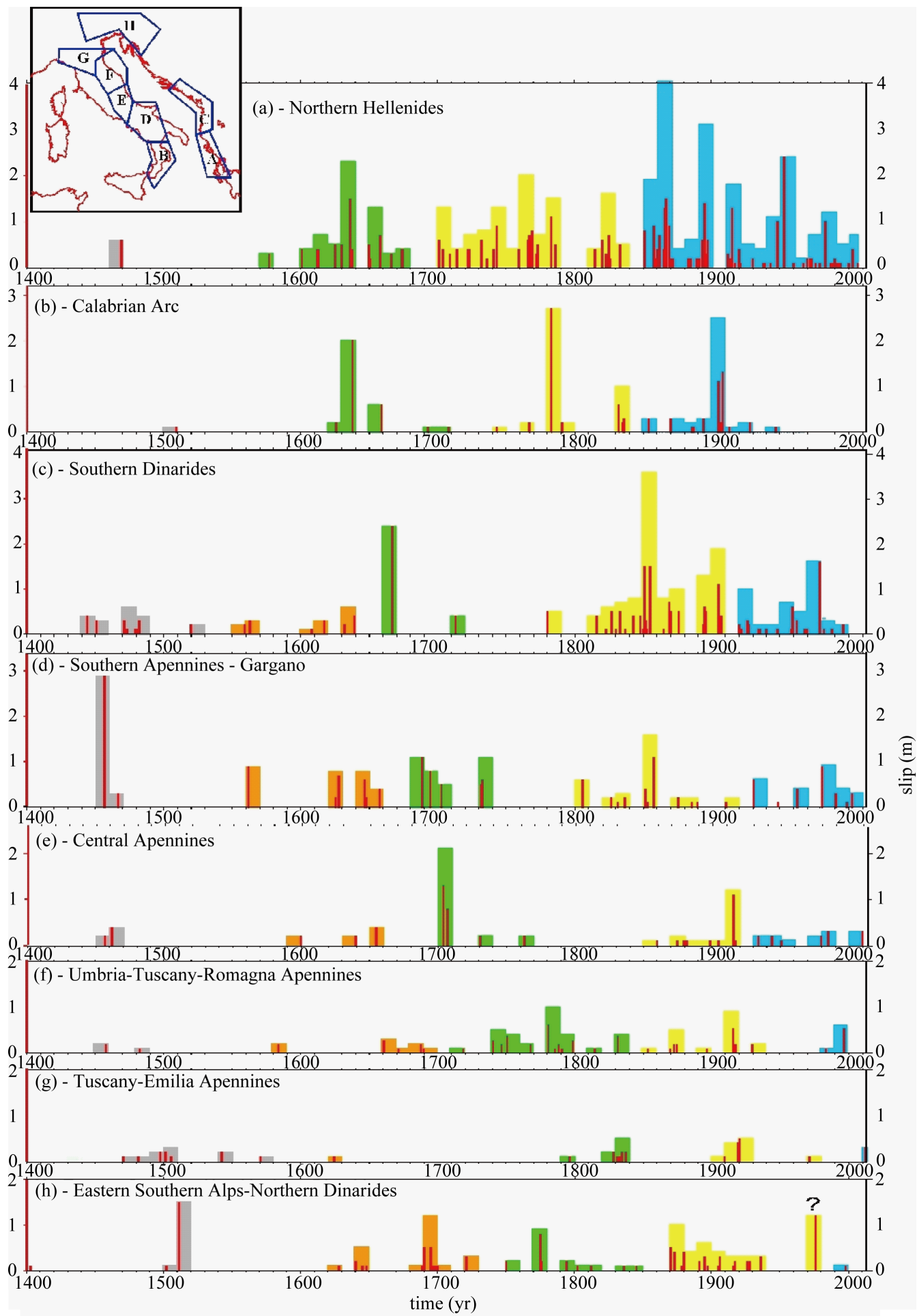

Figure 5. Time patterns of seismic slip associated with major shallow ( $\mathrm{h} \leq 30 \mathrm{~km})$ seismicity $(\mathrm{M} \geq 5.5)$ in the main periAdriatic seismic zones since 1400 A.D. The geometries of the zones considered are shown in the inset. Red bars in the diagrams indicate the total seismic slip (metres) occurred during the related year, computed by the relation $\log _{10} u=-4.8+0.69 M$, where $\mathrm{u}$ is the average seismic slip on the fault (in metres) and $\mathrm{M}$ is the earthquake magnitude [60]. Vertical boxes indicate the sum of seismic slips over decades. Colours tentatively evidence the seismic sequences during which major decoupling earthquakes have undergone a progressive migration from the southern to the northern periAdriatic zones (see text for comments). Seismicity data are given by [2]. 
information can best represent the effects of major decoupling earthquakes on the related acceleration of the Adriatic plate with respect to the surrounding structures [2] [3]. In particular, the total seismic slip developed over consecutive intervals of ten years may provide insights into how relative plate displacement was concentrated in time and how rapidly the surrounding structures have been stressed by such process. In fact, it is known that the brittle and frictional behaviour of rocks, and thus the probability of seismic activation, is favoured by higher and higher strain rate values [61]-[64].

The time patterns shown in Figure 5 point out that in the zones considered seismic slip is mostly discontinuous over time, with periods of high activity separated by almost quiescent phases. Furthermore, one could recognize a progressive northward migration of seismic crises, through the eastern (Northern Hellenides and Dinarides) and western (Apennines) boundaries of Adria, up to reach the northernmost boundary zones (Eastern Southern Alps and Northern Dinarides). The presumed migrating seismic sequences are tentatively evidenced by different colours (grey, orange, green, yellow and blue in Figure 5).

The first two sequences cannot easily be recognized for the most southern Adriatic sectors (Northern Hellenides and Calabria), perhaps due to scanty historical information, while some tendency to migrate northward can be recognized for the other periAdriatic zones.

The third sequence (green in Figure 5) was presumably triggered by a considerable increase of seismic activity in the Northern Hellenides during the first decades of the XVII century. This crisis was then followed by a significant increase of seismic activity at almost all other periAdriatic zones, until when it reached the northern front of Adria through the second half of the XVIII century. At the northern Adriatic front, major seismic activity continued in the XVIII century and then underwent a drastic reduction for a relatively long period, until 1870.

A drastic increase of seismic activity at the Northern Hellenides at the beginning of the XVIII century may have triggered a new seismic sequence (yellow in Figure 5). Another seismic period soon occurred in the same zone from 1815 to 1826. This sequence continued with several major events in the Albania, Southern Dinarides and Southern Apennines. In the Central Apennines, a relatively long period of moderate seismic activity was interrupted by a very strong shock in 1915 (Fucino basin, $M=7.0$ ), which was followed by several strong earthquakes in the Northern Apennines in the period 1916-1920. The space-time distribution of major events during the above seismic sequence (1915-1920) is consistent with the tectonic implications of the proposed tectonic context in the Apennine belt, as argued by [1] [59]. In particular, the numerical modelling of the effects of the post-seismic relaxation induced by the 1915 Fucino and subsequent (1916-1920) strong earthquakes [57] [58] shows that each event of such crisis just occurred when the respective source zone was reached by the highest values of the strain and strain rate perturbation induced by the previous shocks. Moreover, such quantification points out that the strain regimes associated with the above post-seismic perturbations mainly agree with the styles of seismic faulting recognized at the Apennine zones activated during the 1916-1920 sequence.

The last presumed seismic sequence (blue in Figure 5) was triggered by a phase of very high seismic activity in the Northern Hellenides (from about 1850 to 1872), which was soon followed by another crisis, roughly lasting from 1885 to 1897. As in previous cases, these crises were accompanied by major earthquakes in Calabria $(1870 \mathrm{M}=6.1,1894 \mathrm{M}=6.1,1905 \mathrm{M}=6.9,1908 \mathrm{M}=7.2)$.

Then, seismic activity occurred in the southern and central sectors of the Dinarides and Apennines, whereas the northern sectors of those belts have so far been affected by relatively low activity, only constituted by one major seismic crisis in the Eastern Southern Alps (1976, $\mathrm{M}=6.5,6.0)$ and few moderate shocks (Parma 1971, $\mathrm{M}=5.7$; Norcia 1979, $\mathrm{M}=5.9$; Gubbio 1984, $\mathrm{M}=5.7$; Colfiorito 1997, $\mathrm{M}=$ 5.7, 6.0, 5.5, 5.7 and ModenaFerrara 2012, $M=5.9,5.8$ in the Northern Apennines. This evidence could imply that the ongoing sequence has not yet undergone a full development, as it is also suggested by the spatial distribution of major earthquakes in the last 3 sequences (Figure 6).

Thus, assuming that seismic activity in the periAdriatic zones is characterized by a systematic tendency to migrate from south to north, the evidence shown in Figure 5 and Figure 6 would suggest that at present the probability of major earthquakes in the northern zones (Northern Apennines, Northern Dinarides and Eastern Southern Alps) is significantly higher than the one in the southern zones (Calabrian Arc and Southern Apennines). An intermediate probability may tentatively be assigned to the Central Apennines, where the seismic energy so far released during the ongoing sequence phase (i.e., Maiella 1933, $M=6.0$, 5.1; Laga $1943 \mathrm{M}=5.8$; Gran Sasso $1950 \mathrm{M}=5.1$, 5.7 and L'Aquila $2009 \mathrm{M}=6.3$ ) is lower than the one released in previous sequences.

Other significant evidence in support of the hypothesis that the present probability of major shocks in the 

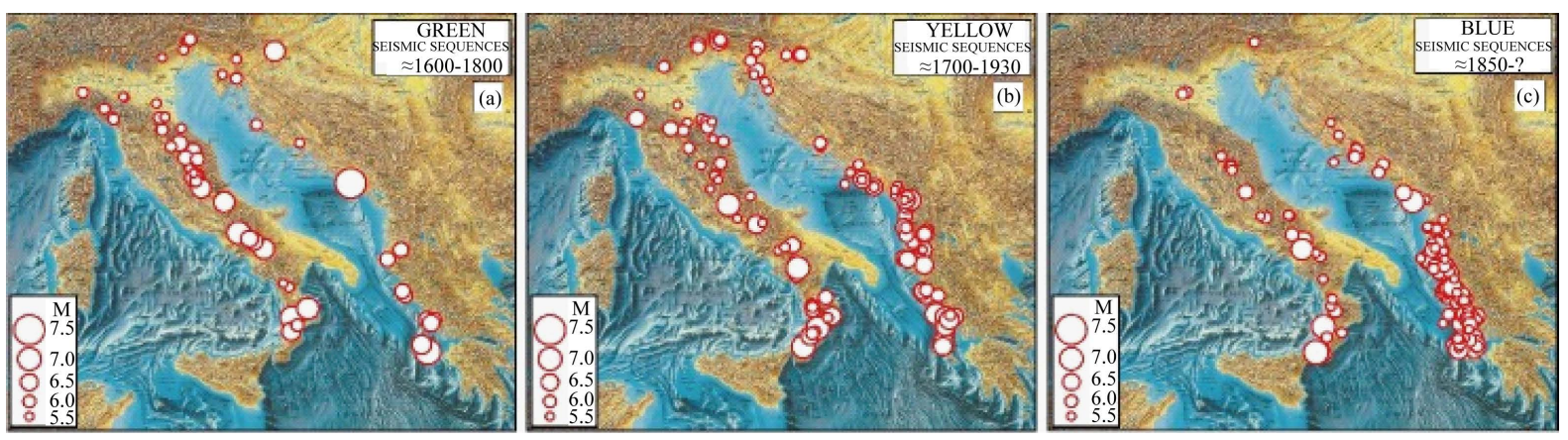

Figure 6. Spatial distribution of major earthquakes $(M \geq 5.5)$ occurred during the last three migrating seismic sequences: green (a), yellow (b) and blue (c), evidenced in Figure 5.

southern Italian regions (Southern Apennines and Calabria) is lower than in the northern zones (Northern Apennines, Eastern Southern Alps and Northern Dinarides) are provided by the two significant correlations so far recognized between major seismic crises in southern Italian and Hellenic/Dinaric sectors [1]-[3] [59].

\section{Migrations of Seismicity along the Apennine Belt and Underlying Tectonic Mechanism}

Being particularly interested in recognizing seismic hazard in the Italian territory, we have carried out a careful analysis of the distribution of major earthquakes that have occurred in the Apennine belt during the periAdriatic sequences shown in Figure 5. This study mainly aims at checking the compatibility between the spatio temporal distribution of major earthquakes and the implications of the proposed short-term tectonic evolution [1]-[3] [7] [8] [11], synthetically described in the following.

When a major decoupling earthquake occurs in the Southern Apennines (Irpinia, Matese or Benevento extensional/transtensional zones), the Molise-Sannio wedge undergoes a sudden acceleration, increasing its belt parallel push on the eastern sector of the Lazio-Abruzzi platform (ELA wedge) in the Central Apennines (Figure 3). This causes a strengthening of shear stress between the pushed and the non-pushed sectors of the LA platform, favouring seismic sliding at the main belt-parallel faults sytems (L'Aquila and Fucino). When such context ends up with a major shock at one of those faults, the related decoupled sector of LA accelerates, increasing its tectonic load (and earthquake probability) on the RMU wedge in the Northern Apennines. The effect that this sudden stress increase can produce in the RMU wedge depends on which fault system is activated in the Central Apennines. When seismic decoupling occurs at the L'Aquila fault, the sector of ELA that undergoes acceleration is relatively narrow, mainly concerning the Gran Sasso Arc (Figure 3). Correspondingly, the sector of the RMU wedge that is stressed by such accelerated push is narrow as well. This interpretation may explain why a major belt parallel fault system, roughly running along the northward prosecution of the L'Aquila fault system (Norcia-Colfiorito-Gualdo Tadino-Gubbio, Figure 3), has recently (Pleistocene) developed within the RMU wedge. Such major fracture and its northward prosecution by the Upper Tiber Valley and Romagna Apennines/Forlì zones might represent the inner extensional/transtensional border of a wedge that will be hereafter recalled as Outer Romagna-Marche-Umbria (ORMU). The geometry of such wedge mainly corresponds to the northern part of the green area shown in Figure 4.

When, instead, the Fucino fault system is activated, the decoupled and accelerated sector of the LA platform is wider. Consequently, the stressed sector of the RMU wedge in the Northern Apennines is wider as well (Figure 2). An idea about the possible consequences of this case is given by the pattern of seismicity that followed the strong earthquake that activated the Fucino fault system in $1915(\mathrm{M}=7.0)$. One major difference with respect to the other sequences (when the L'Aquila fault system was involved) is the fact that no sectors of the No-Cf-GT-Gu fault system were activated. The hypothesis that the accelerated RMU wedge after the $1915 \mathrm{Fu}-$ cino moved as an almost unique body (without major internal discontinuities) is supported by the fact that in the subsequent few years (1916-1920) 7 strong shocks $(\mathrm{M}>5.5)$ took place at the main seismic boundaries of the northern part of that sector and of the TE wedge, i.e. the 1916 Rimini, 1917 Upper Tiber Valley, 1918 Romagna Apennines, 1919 Mugello and 1920 Garfagnana/Lunigiana events [57] [58].

In the following, we discuss on how the tectonic setting described above may have influenced the migration 
of seismicity along the Apennine belt, during the periAdriatic seismic sequences shown in Figure 5.

The first sequence (grey in Figure 5) was presumably triggered in 1456 by the occurrence of strong earthquakes in the Southern Apennines (Molise, $M=7.2,7.0,6.3$, Table 1, Figure 7(a)), followed by another major shock in Irpinia in 1466, $M=6.1$ ). In the same period, strong shocks occurred in the Central Apennines (Aquila zone 1456, $M=5.8 ; 1461, M=6.4$ ) and in the Marche-Umbria Apennines (Upper Tiber Valley, 1458, $M=5.8$ ).

The prosecution of this seismic sequence (Figure 7(b)) presents a clear northward migration, involving the inner and outer borders of the Romagna and Toscana-Emilia Apennines (southern Romagna 1483, $\mathrm{M}=5.7$; Garfagnana 1481, $\mathrm{M}=$ 5.6; Lunigiana 1497, $\mathrm{M}=5.9$; Modena Apennines 1501, $\mathrm{M}=6.0$; Bologna 1505, $\mathrm{M}=$ 5.6). Strong seismicity reached the northern Adria border (Northern Dinarides) around the beginning of the following century (1511 Slovenia, $\mathrm{M}=7.0$ ).

Table 1. Major earthquakes ( $M \geq 5.5)$ occurred in the Apennine belt during the first periAdriatic sequence (grey in Figure 5), mapped in Figure 7 [65] [66]. M = magnitude, I = Mercalli-Cancani-Sieberg macroseismic intensity.

\begin{tabular}{|c|c|c|c|c|}
\hline y-m-d & Lat & Long & $\mathbf{M}$ & I \\
\hline 1456-12-5 & 41.30 & 14.71 & 7.2 & 11 \\
\hline 1456-12-5 & 41.18 & 14.87 & 7.0 & 11 \\
\hline 1456-12-5 & 42.20 & 13.93 & 5.8 & 10.5 \\
\hline $1456-12-5$ & 41.08 & 15.67 & 6.3 & 9 \\
\hline 1458-4-26 & 43.46 & 12.24 & 5.8 & 8.5 \\
\hline $1461-11-27$ & 42.31 & 13.54 & 6.4 & 10 \\
\hline 1466-1-15 & 40.76 & 15.33 & 6.1 & 8.5 \\
\hline 1470-4-11 & 44.16 & 11.04 & 5.6 & 8 \\
\hline $1481-5-7$ & 44.27 & 10.13 & 5.6 & 8 \\
\hline 1483-8-11 & 44.16 & 12.23 & 5.7 & 8 \\
\hline $1497-3-3$ & 44.25 & 9.92 & 5.9 & 8.5 \\
\hline $1501-6-5$ & 44.52 & 10.84 & 6.0 & 9 \\
\hline $1505-1-3$ & 44.51 & 11.23 & 5.6 & 8 \\
\hline $1511-3-26$ & 46.20 & 13.43 & 7.0 & 9 \\
\hline
\end{tabular}
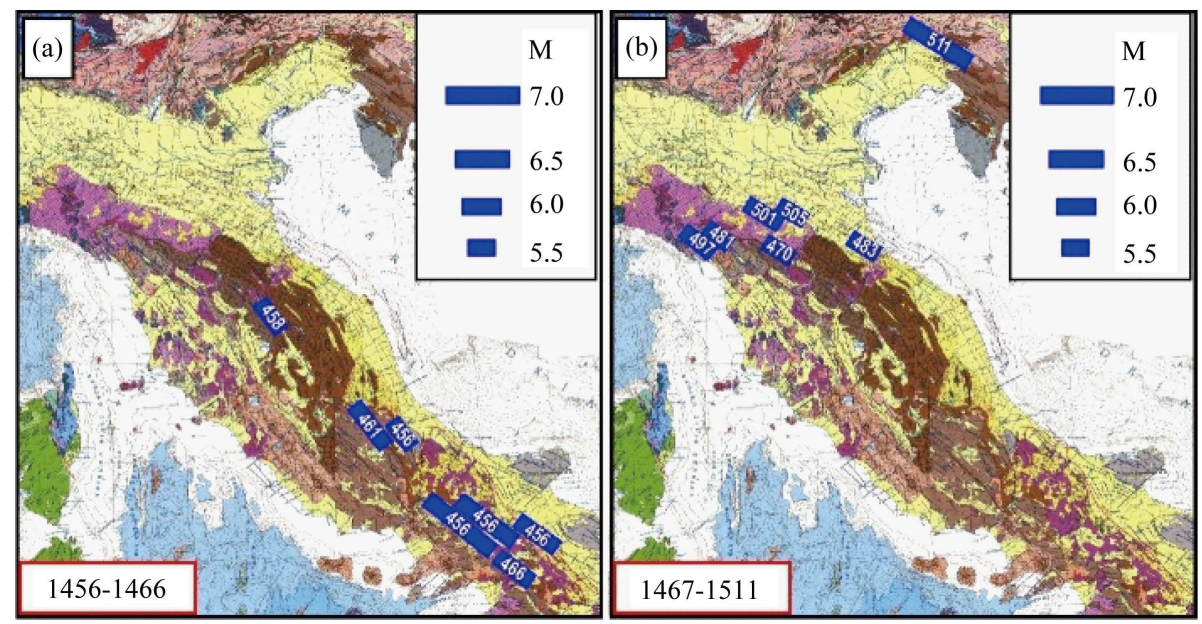

Figure 7. Distribution of major earthquakes $(M \geq 5.5)$ in the Apennine belt during the first periAdriatic sequence (Figure 5). The seismicity pattern in the Apennines is divided in two phases: (a) (1456-1466) and (b) (1467-1511), in order to point out the progressive northward migration of seismicity. See text for comments. 
The second sequence (orange in Figure 5) did not involve very strong earthquakes (like the ones occurred in the other sequences) (Table 2). Furthermore, the northward migration of seismicity in the study area is rather uncertain. One could tentatively recognize two sub-sequences, as shown in the Figures 8(a)-(c) respectively.

During the third sequence (green in Figure 5), seismic activity in the Apennines underwent a clear migration from South to North (Table 3 and Figure 9). In the first phase (Figure 9(a)), lasting about 15 years, strong seismicity only occurred in the Southern Apennines (first) and Central Apennines (then). In the second phase (Figure 9(b)), seismicity mostly involved the Marche-Umbria sector (Northern Apennines), while some activity continued in the Southern Apennines (1732). In the third phase (Figure 9(c)), seismicity first occurred in the Central Apennines (1762) and then, from 1768 to 1799, a number of major earthquakes activated most sectors of the inner extensional boundary of the Marche-Umbria wedge (Colfiorito, Upper Tiber Valley, Cagli, Romagna Appennines, Forlì zone) and of the outer compressional border of the same wedge (Marche Apennines, Rimini zone and Ferrara buried folds).

In the last phase (Figure 9(d)), seismicity mostly affected the inner (Garfagnana-Lunigiana) and outer (Padanian) borders of the Toscana-Emilia units, in the northernmost sector of the Apennine belt. In the same period, two events continued to activate the Marche-Umbria Apennines $(1815,1832)$.

A peculiar feature of this sequence is the long time (about 150 years) that it took to migrate from the Southern Apennines to the northernmost zones of the belt.

During the fourth periAdriatic sequence (yellow in Figure 5), strong seismicity in the Apennines may be divided in 3 phases (Table 4 and Figure 10). In the first phase (Figure 10(a)), seismicity mainly took place in the Southern Apennines. In the second phase (Figure 10(b)) seismicity mostly affected the Northern Apennines and Eastern Alps, surprisingly by-passing the Central Apennines, where only few moderate shocks occurred in marginal zones. In this regard, it must be pointed out that strong seismicity in the Central Apennines underwent a

Table 2. Major earthquakes $(M \geq 5.5)$ that occurred in the Apennine belt during the second periAdriatic sequence (orange in Figure 5). Map in Figure 8. See caption of Table 1.

\begin{tabular}{|c|c|c|c|c|}
\hline$y-m-d$ & Lat & Long & $\mathbf{M}$ & $\mathbf{I}$ \\
\hline $1561-7-31$ & 14.72 & 40.69 & 5.6 & 8 \\
\hline $1561-8-19$ & 15.51 & 40.56 & 6.8 & 10 \\
\hline $1584-9-10$ & 11.99 & 43.86 & 5.8 & 9 \\
\hline 1599-11-6 & 13.02 & 42.72 & 6.0 & 9 \\
\hline $1624-3-19$ & 11.85 & 44.64 & 5.5 & 7.5 \\
\hline $1625-9$ & 40.96 & 15.82 & 5.8 & 8.5 \\
\hline $1627-7-30$ & 41.74 & 15.34 & 6.7 & 10 \\
\hline $1639-10-7$ & 42.64 & 13.26 & 5.9 & 9.5 \\
\hline $1646-5-31$ & 41.73 & 15.76 & 6.6 & 9.5 \\
\hline $1647-5-5$ & 41.73 & 15.56 & 5.9 & 7.5 \\
\hline $1654-7-24$ & 41.63 & 13.68 & 6.3 & 9.5 \\
\hline $1657-1-29$ & 41.73 & 15.39 & 6.4 & 8.5 \\
\hline $1661-3-22$ & 44.02 & 11.90 & 6.1 & 9 \\
\hline $1672-4-14$ & 43.94 & 12.58 & 5.6 & 8 \\
\hline $1688-4-11$ & 44.39 & 11.94 & 5.8 & 8.5 \\
\hline $1690-12-23$ & 43.58 & 13.59 & 5.6 & 8.5 \\
\hline $1695-2-25$ & 45.80 & 11.95 & 6.5 & 10 \\
\hline $1695-6-11$ & 42.61 & 12.11 & 5.7 & 8.5 \\
\hline $1700-7-28$ & 46.43 & 12.87 & 5.6 & 8.5 \\
\hline $1721-1-12$ & 45.30 & 14.40 & 6.1 & 9 \\
\hline
\end{tabular}




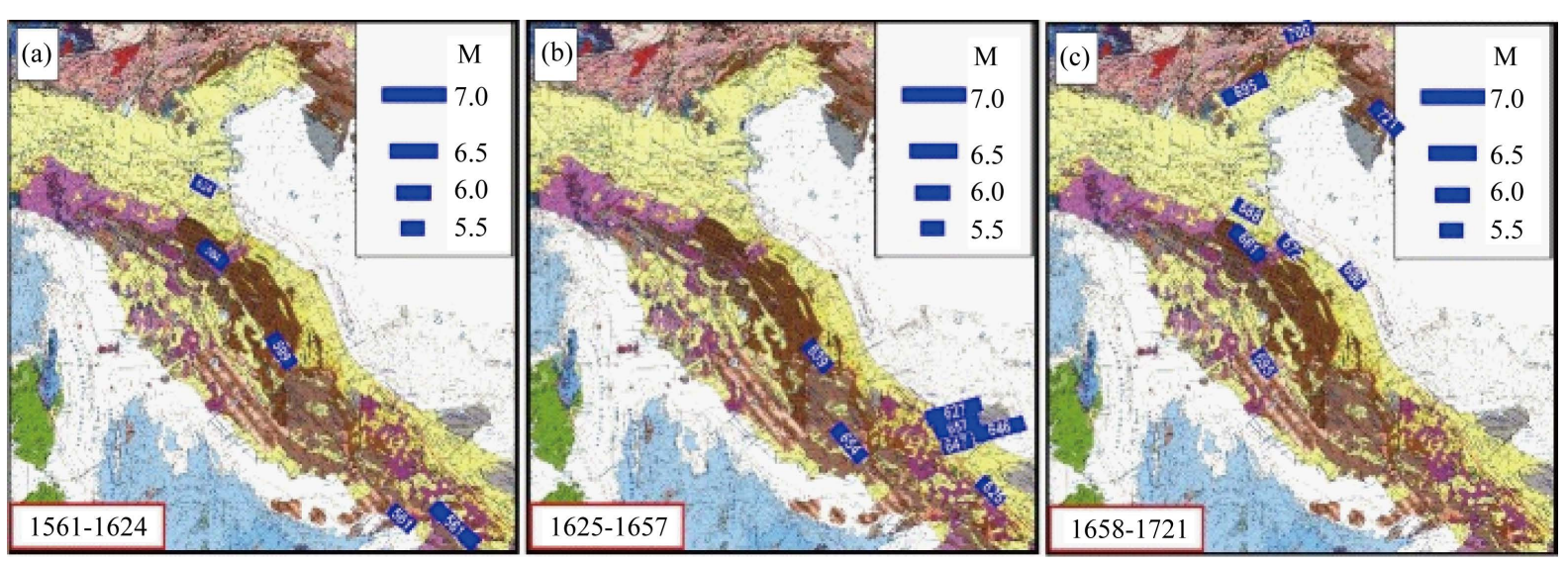

Figure 8. Distribution of major earthquakes in the Apennine belt during the second sequence (Figure 5). Two sub-sequences could be tentatively recognized. The first may concern the time interval 1561-1624 (a) and the second the two phases shown in (b) (1625-1657) and (c) (1658-1721) respectively. See text for comments.


Figure 9. Distribution of major earthquakes in the Apennine belt during the third periAdriatic sequence (Figure 5). The seismicity pattern in the Apennine belt is divided in 4 phases: (a) (1688-1706); (b) (1707-1751); (c) (1752-1802) and (d) (1803-1837), to point out the progressive northward migration of seismicity in the Apennine belt. See text for comments. 
Table 3. Major earthquakes $(M \geq 5.5)$ occurred in the Apennine belt during the third periAdriatic sequence (green in Figure 5). Map in Figure 9. See caption of Table 1.

\begin{tabular}{|c|c|c|c|c|}
\hline$y-m-d$ & Lat & Long & $\mathbf{M}$ & I \\
\hline $1688-6-5$ & 41.28 & 14.56 & 7.0 & 11 \\
\hline $1694-9-8$ & 40.86 & 15.41 & 6.8 & 10 \\
\hline $1702-3-14$ & 41.12 & 14.99 & 6.5 & 10 \\
\hline $1703-1-14$ & 42.71 & 13.07 & 6.7 & 11 \\
\hline $1703-1-16$ & 42.62 & 13.10 & 5.9 & 8 \\
\hline $1703-2-2$ & 42.43 & 13.29 & 6.7 & 10 \\
\hline $1706-11-3$ & 42.08 & 14.08 & 6.8 & 10.5 \\
\hline $1719-6-27$ & 42.88 & 13.05 & 5.5 & 8 \\
\hline $1730-5-12$ & 42.75 & 13.12 & 5.9 & 9 \\
\hline $1731-3-20$ & 41.27 & 15.76 & 6.5 & 9 \\
\hline $1732-1-29$ & 41.06 & 15.06 & 6.6 & 10.5 \\
\hline $1741-4-24$ & 43.42 & 13.01 & 6.2 & 9 \\
\hline $1747-4-17$ & 43.20 & 12.77 & 5.9 & 9 \\
\hline $1751-7-27$ & 43.22 & 12.74 & 6.3 & 10 \\
\hline $1762-10-6$ & 42.31 & 13.59 & 6.0 & 9 \\
\hline $1768-10-19$ & 43.94 & 11.90 & 5.9 & 9 \\
\hline $1776-7-10$ & 46.23 & 12.71 & 5.8 & 8.5 \\
\hline $1781-4-4$ & 44.25 & 11.80 & 5.9 & 9.5 \\
\hline 1781-6-3 & 43.60 & 12.51 & 6.4 & 10 \\
\hline $1781-7-17$ & 44.27 & 11.99 & 5.6 & 8 \\
\hline 1785-10-9 & 42.54 & 12.79 & 5.7 & 8.5 \\
\hline $1786-12-25$ & 43.99 & 12.56 & 5.6 & 8 \\
\hline 1789-9-30 & 43.51 & 12.22 & 5.8 & 9 \\
\hline $1791-10-11$ & 42.95 & 12.86 & 5.5 & 8 \\
\hline 1794-6-7 & 46.31 & 12.82 & 6.0 & 8.5 \\
\hline $1796-10-22$ & 44.62 & 11.67 & 5.6 & 7 \\
\hline $1799-7-28$ & 43.19 & 13.15 & 6.1 & 9 \\
\hline $1802-5-12$ & 45.42 & 9.84 & 5.6 & 8 \\
\hline $1805-7-26$ & 41.50 & 14.47 & 6.6 & 10 \\
\hline $1806-8-26$ & 41.72 & 12.72 & 5.5 & 8 \\
\hline $1812-10-25$ & 46.03 & 12.59 & 5.7 & 7.5 \\
\hline $1815-9-3$ & 42.83 & 13.02 & 5.5 & 8 \\
\hline $1826-2-1$ & 40.52 & 15.73 & 5.8 & 8 \\
\hline $1828-10-9$ & 44.82 & 9.05 & 5.8 & 8 \\
\hline 1831-9-11 & 44.75 & 10.54 & 5.5 & 7.5 \\
\hline $1832-1-13$ & 42.98 & 12.60 & 6.3 & 10 \\
\hline $1832-3-13$ & 44.76 & 10.49 & 5.5 & 7.5 \\
\hline 1834-2-14 & 44.43 & 9.85 & 5.8 & 9 \\
\hline $1836-6-12$ & 45.81 & 11.82 & 5.5 & 8 \\
\hline $1836-11-20$ & 40.14 & 15.78 & 6.0 & 8 \\
\hline $1837-4-11$ & 44.17 & 10.18 & 5.8 & 9 \\
\hline
\end{tabular}


Table 4. Major earthquakes $(M \geq 5.5)$ occurred in the Apennine belt during the fourth periAdriatic sequence (yellow in Figure 5). Map in Figure 10. See caption of Table 1.

\begin{tabular}{|c|c|c|c|c|}
\hline$y-m-d$ & Lat & Long & $\mathbf{M}$ & I \\
\hline 1851-8-14 & 40.95 & 15.67 & 6.4 & 10 \\
\hline $1853-4-9$ & 40.82 & 15.21 & 5.6 & 8 \\
\hline $1854-2-12$ & 43.03 & 12.58 & 5.6 & 8 \\
\hline $1857-12-16$ & 40.35 & 15.84 & 7.0 & 11 \\
\hline 1859-8-22 & 42.83 & 13.10 & 5.5 & 8.5 \\
\hline $1870-3-1$ & 45.40 & 14.40 & 5.6 & 8 \\
\hline $1870-10-30$ & 44.13 & 12.06 & 5.6 & 8 \\
\hline $1873-3-12$ & 43.09 & 13.24 & 6.0 & 8 \\
\hline $1873-6-29$ & 46.16 & 12.38 & 6.3 & 9.5 \\
\hline $1874-12-6$ & 41.65 & 13.83 & 5.5 & 7.5 \\
\hline $1875-3-17$ & 44.21 & 12.57 & 5.9 & 8 \\
\hline $1875-12-6$ & 41.69 & 15.68 & 6.0 & 8 \\
\hline $1879-2-23$ & 42.77 & 13.04 & 5.6 & 8 \\
\hline $1881-9-10$ & 42.23 & 14.28 & 5.6 & 8 \\
\hline $1885-12-26$ & 41.54 & 14.68 & 5.5 & 7.5 \\
\hline $1889-12-8$ & 41.83 & 15.69 & 5.7 & 7 \\
\hline 1891-6-7 & 45.56 & 11.16 & 5.9 & 8.5 \\
\hline $1898-6-27$ & 42.41 & 12.90 & 5.5 & 8 \\
\hline $1901-10-30$ & 45.58 & 10.49 & 5.7 & 8 \\
\hline $1904-2-24$ & 42.10 & 13.32 & 5.6 & 8.5 \\
\hline 1909-1-13 & 44.58 & 11.69 & 5.5 & 6.5 \\
\hline $1910-6-7$ & 40.9 & 15.42 & 5.7 & 8 \\
\hline $1914-10-27$ & 43.91 & 10.60 & 5.8 & 7 \\
\hline $1915-1-13$ & 42.01 & 13.53 & 7.0 & 11 \\
\hline $1916-5-17$ & 44.14 & 12.72 & 6.0 & 0 \\
\hline 1916-8-16 & 44.03 & 12.78 & 6.1 & 8 \\
\hline 1916-8-16 & 44.17 & 12.92 & 5.5 & 0 \\
\hline $1916-11-16$ & 42.65 & 13.17 & 5.5 & 8 \\
\hline $1917-4-26$ & 43.47 & 12.13 & 5.9 & 9.5 \\
\hline $1918-11-10$ & 43.92 & 11.93 & 5.9 & 9 \\
\hline $1919-6-29$ & 43.96 & 11.48 & 6.3 & 10 \\
\hline $1920-9-7$ & 44.19 & 10.28 & 6.5 & 10 \\
\hline 1926-1-1 & 45.76 & 14.28 & 5.9 & 7.5 \\
\hline $1928-3-27$ & 46.37 & 12.97 & 5.8 & 9 \\
\hline $1930-10-30$ & 43.66 & 13.33 & 5.8 & 8 \\
\hline $1936-10-18$ & 46.09 & 12.38 & 6.1 & 9 \\
\hline
\end{tabular}



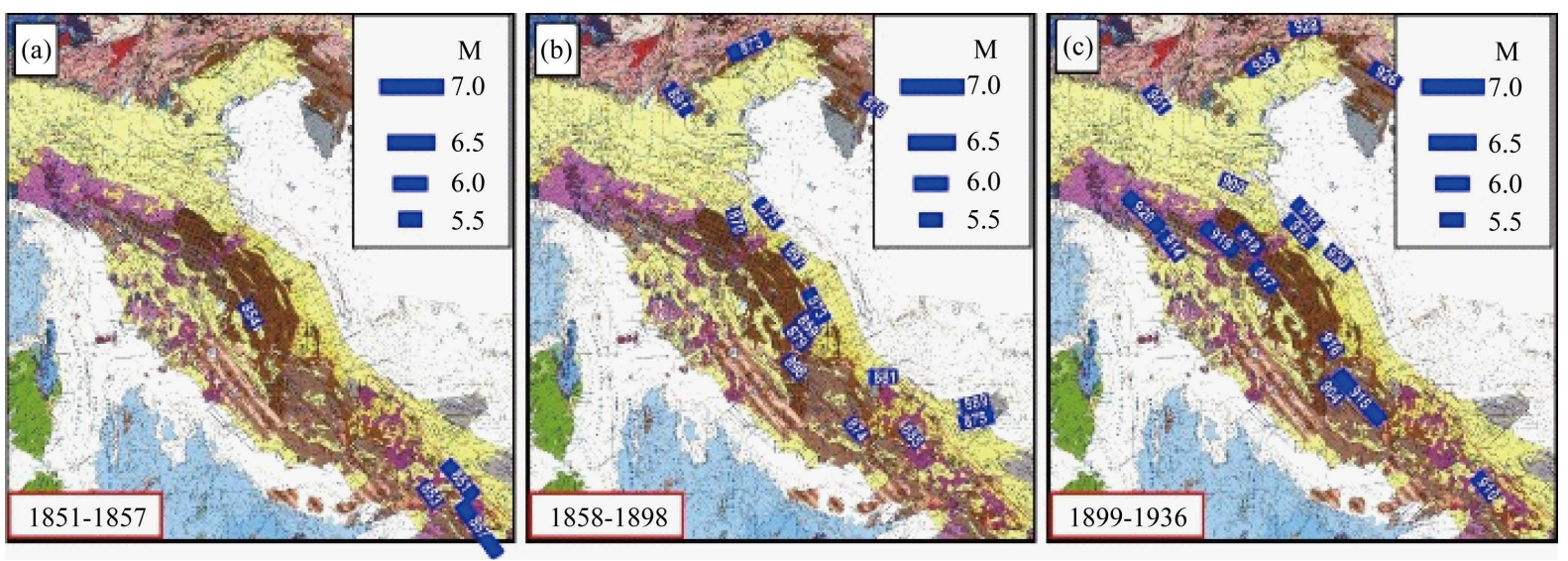

Figure 10. Distribution of major earthquakes in the Apennine belt during the fourth periAdriatic sequence (Figure 5). The seismicity pattern in the Apennine belt is divided in 3 phases: (a) (1851-1857); (b) (1858-1898) and (c) (1899-1936), to point out the progressive northward migration of seismicity. See text for comments.

long quiescence (1762-1904), the longest in the known history. Thus, it might be non-casual the fact that this long quiescence ended up with the strongest shock ever occurred in the Central Apennines (1915, $\mathrm{M}=7.0$ ). Furthermore, one must consider that the above event involved the Fucino fault system, which, as far as we know, was never activated with such a magnitude [65].

As discussed in previous works [1] the tectonic implications of the 1915 Fucino earthquake may explain the exceptional seismic activity that occurred in the Northern Apennines (Figure 10(c)), with 7 major earthquakes ( $\mathrm{M}>$ 5.5), in the following 5 years (1916-1920). Furthermore, the numerical quantification of the post seismic relaxation triggered by the above earthquake [57] [58] has provided plausible explanation for the times of the shocks occurred in the period 1916-1920. Another evidence in support of the proposed tectonic interpretation is the fact that the seismicity pattern which followed the 1915 Fucino shock did not involve the activation of the No-Cf-GT-Gu fault system. In fact, the sector of the LA wedge which was decoupled by the 1915 Fucino shock did not strengthen shear stress in the above fault system. The activity in the Northern Apennine was then followed by major shocks in the Eastern Southern Alps.

In the last sequence (blue in Figure 5), major seismicity in the Apennine belt has so far occurred in the Southern and Central Apennines and in the Marche-Umbria sector of the Northern Apennines (Table 5 and Figure 11(a), Figure 11(b)). Only few earthquakes have involved the zones lying more to the north (Parma, 1971; Po Valley, 2012; Eastern Southern Alps 1976, 1998 [65]). As discussed earlier, this pattern suggests that the development of this sequence will most probably involve the tectonic sectors not yet activated of the Northern Apennines.

Another migration of seismicity, involving major shocks in the Southern, Central and Northern Apennines, has developed around the middle of the XIV century (Table 6 and Figure 12). It can be noted a noticeable similarity between this seismic sequence and the one shown in Figure 7, concerning in particular the short time elapsed between the activation of the various Apennine sectors (few years) and the fact that, as far as we know, the reaction of the Northern Apennines has only involved the UTV zone.

\section{Spatio-Temporal Distribution of Minor Seismicity}

Our attempt at identifying a connection between tectonic processes and the spatio-temporal distribution of earthquakes has so far taken into account the strongest seismicity $(M \geq 5.5)$. This choice is mainly due to the wellknown concept that tectonic processes and plate motions are mostly controlled by strong shocks, that involve long decoupling faults and significant values of seismic slip. However, it is reasonable to suppose that the ongoing deformation pattern also influences the spatio-temporal distribution of weaker events, even if the underlying relation is not yet clear. In order to get insights into this problem, we have analysed the most complete and reliable data set now available on minor seismicity in the Italian area, reported in the catalogues [67] [68] and covering the period 1981-2014 (Figure 13).

A first interesting result achieved by this study is the fact that in the last ten years, the number of events with 
Table 5. Major earthquakes ( $M \geq 5.5$ ) occurred in the Apennine belt during the fifth periAdriatic sequence (blue in Figure 5). Map in Figure 11. See caption of Table 1.

\begin{tabular}{|c|c|c|c|c|}
\hline$y-m-d$ & Lat & Long & $\mathbf{M}$ & I \\
\hline $1930-7-23$ & 41.07 & 15.32 & 6.6 & 10 \\
\hline $1933-9-26$ & 42.08 & 14.09 & 6.0 & 9 \\
\hline $1943-10-3$ & 42.91 & 13.65 & 5.8 & 8.5 \\
\hline 1948-8-18 & 41.58 & 15.75 & 5.6 & 7.5 \\
\hline $1950-9-5$ & 42.55 & 13.46 & 5.7 & 8 \\
\hline $1962-8-21$ & 41.23 & 14.93 & 5.7 & 8.5 \\
\hline $1962-8-21$ & 41.23 & 14.95 & 6.1 & 9 \\
\hline $1971-7-15$ & 44.81 & 10.35 & 5.6 & 8 \\
\hline $1976-5-6$ & 46.24 & 13.12 & 6.5 & 9.5 \\
\hline $1976-9-11$ & 46.26 & 13.23 & 5.6 & 7.5 \\
\hline $1976-9-15$ & 46.28 & 13.20 & 5.9 & 0 \\
\hline 1976-9-15 & 46.30 & 13.17 & 6.0 & 8.5 \\
\hline 1979-9-19 & 42.71 & 13.07 & 5.9 & 8.5 \\
\hline $1980-11-23$ & 40.84 & 15.28 & 6.9 & 10 \\
\hline $1984-4-29$ & 43.26 & 12.52 & 5.7 & 7 \\
\hline $1984-5-7$ & 41.67 & 14.06 & 5.9 & 8 \\
\hline $1984-5-11$ & 41.71 & 13.89 & 5.5 & 7 \\
\hline $1990-5-5$ & 40.65 & 15.88 & 5.8 & 7 \\
\hline $1997-9-26$ & 43.02 & 12.89 & 5.7 & 7.5 \\
\hline $1997-9-26$ & 43.01 & 12.85 & 6.0 & 8.5 \\
\hline 1997-10-6 & 43.03 & 12.85 & 5.5 & 7.5 \\
\hline $1997-10-14$ & 42.90 & 12.90 & 5.7 & 7.5 \\
\hline $1998-4-12$ & 46.31 & 13.63 & 5.7 & 6 \\
\hline 2002-10-31 & 41.72 & 14.89 & 5.7 & 7.5 \\
\hline 2002-11-1 & 41.74 & 14.84 & 5.7 & 7 \\
\hline 2009-4-6 & 42.34 & 13.38 & 6.3 & 9 \\
\hline $2012-5-20$ & 44.89 & 11.23 & 5.9 & 0 \\
\hline $2012-5-29$ & 44.85 & 11.09 & 5.8 & 0 \\
\hline
\end{tabular}

Table 6. Major earthquakes $(M \geq 5.5)$ that occurred in the Apennine belt during another migrating sequence that developed around the middle of the XIV century (Figure 12). See text for comments.

\begin{tabular}{ccccc}
\hline y-m-d & Lat & Long & M & I \\
\hline $1348-9-13$ & 41.92 & 13.10 & 5.6 & 8 \\
$1349-9-9$ & 42.27 & 13.12 & 5.9 & 9 \\
$1349-9-9$ & 42.02 & 13.97 & 6.0 & 9 \\
$1349-9-9$ & 41.56 & 13.90 & 5.9 & 8.5 \\
$1349-9-9$ & 41.56 & 13.90 & 6.6 & 10 \\
$1352-12-25$ & 43.47 & 12.13 & 6.4 & 9 \\
$1353-1-1$ & 43.57 & 12.13 & 6.0 & 9 \\
$1361-7-17$ & 41.20 & 15.56 & 6.0 & 9 \\
\hline
\end{tabular}



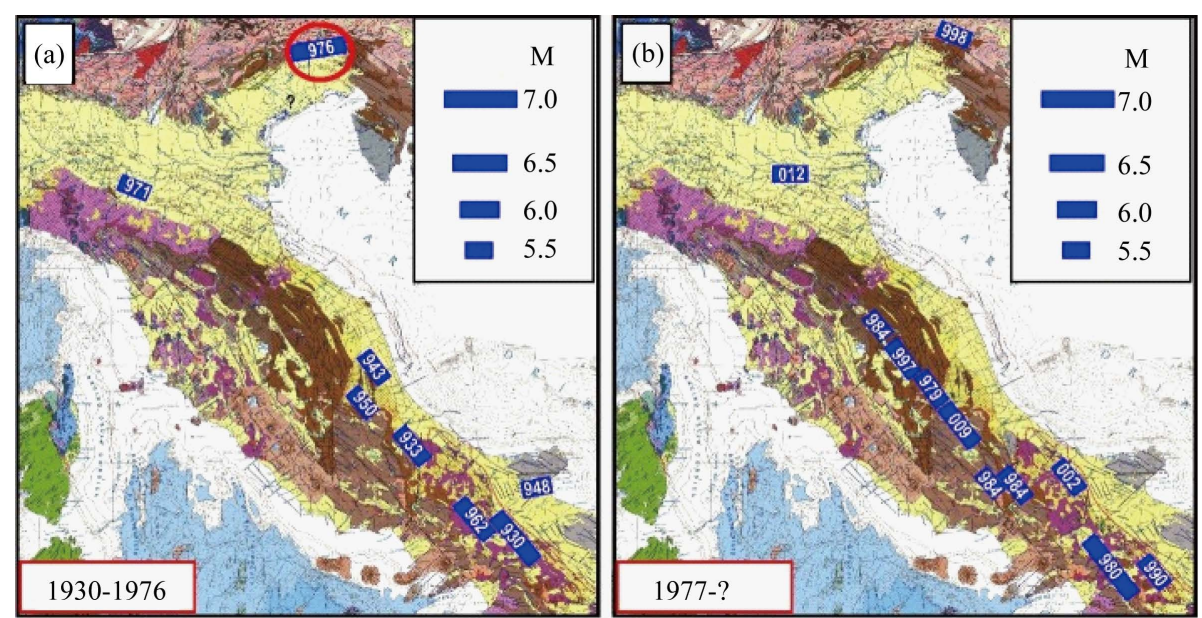

Figure 11. Distribution of major earthquakes in the Apennine belt during the last periAdriatic sequence (blue in Figure 5). In the first phase (a), major seismicity has mainly involved the Southern and Central Apennines, increasing tectonic load in the Northern Apennines. In this last zone, seismicity has then affected the Umbrian Apennines (b). More recently, major earthquakes have occurred at the L'Aquila fault system (increasing the mobility of the Gran Sasso wedge) and at the Ferrara buried folds. See text for comments.

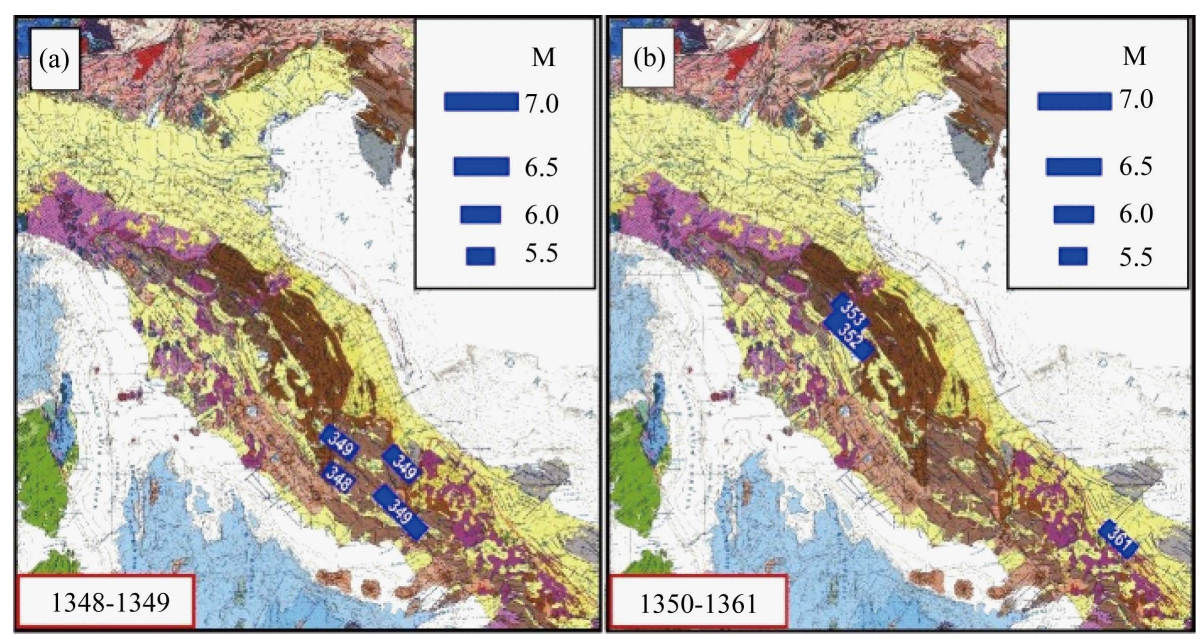

Figure 12. Distribution of major earthquakes in the Apennine belt during another possible migration that developed around the middle of the XIV century (Table 6). See text for comments.

$\mathrm{M}>2$ in the Northern Apennines, i.e. the zone recognized as the most probable site of next strong earthquakes, is considerably higher than in the other zones of the Italian peninsula (Figure 13). For instance, this could imply that in the above zone the present tectonic load is stronger than in the other zones, in line with the indications derived by the analysis of major earthquakes. The table in Figure 13 indicates that the above seismicity pattern is a relatively recent phenomenon, being most evident in the latest years.

In order to gain insights into the role plaid by minor seismicity in the seismotectonic context of the Central and Northern Apennines, we have considered the time patterns of that activity in the various sectors of the belt (Figure 14), with particular regard to the zones located along the boundaries of the ORMU wedge.

In order to provide information on the two main aspects of seismic activity, each diagram reports both the annual numbers of events with $\mathrm{M}>2$ and the total energy released, synthesized by the equivalent magnitude (Me). The first datum, accompanied by the spatial distribution of epicentres (Figure 15), may help to roughly estimate the size of the involved decoupling zones, where the whole system of activated microfaults is located, while the second datum (Me) may inform about the whole entity of the seismic crisis. 


\begin{tabular}{|l|c|c|c|c|c|c|}
\hline \multicolumn{2}{|c|}{ Seismicity $(\mathrm{M} \geq 2)$ between 1-1-2005 and 31-12-2014 $(\mathrm{h} \leq 30 \mathrm{Km})$} \\
\hline & 2014 & 2012 & 2010 & 2008 & 2006 \\
\hline A) Eastern Alps & 2011 & 2009 & 2007 & 2005 \\
\hline B) Padanian buried folds & 95 & 88 & 92 & 59 & 74 \\
\hline C) Tuscany-Emilian Apennines & 85 & 1701 & 22 & 20 & 14 \\
\hline D) Tuscany-Romagna-Umbria Apennines & 540 & 254 & 231 & 460 & 129 \\
\hline E) Central Apennines & 1274 & 497 & 549 & 336 & 764 \\
\hline F) Southern Apennines & 319 & 380 & 3777 & 166 & 219 \\
\hline G) Calabria & 286 & 137 & 141 & 141 & 200 \\
\hline
\end{tabular}

Figure 13. Number of shocks with $M \geq 2$ that have occurred since 2005 in the main seismic zones of the Italian peninsula during different time intervals. The geometry of the zones considered are shown in the map. Seismicity data from [68]. Red numbers in the table refer to the zone that has been earlier identified as the most prone to next strong earthquakes. Blue numbers are influenced by the aftershocks of the major earthquakes that have occurred in the related zones during the period considered (L'Aquila 2009, $M$ = 6.3; Po Valley 2012, $M=5.9$, 5.8 and Lunigiana-Garfagnana 2013, $M=4.8,5.2$ ).

The diagrams of Figure 14 show that in each zone seismic activity is relatively low or null over most of the period considered, but for some short time intervals, during which a significantly higher level can be recognized. To try a recognition of eventual significant connections between the phases of increased seismicity and tectonic processes, one could tentatively suppose that an increase of seismicity reveals an acceleration of the relative motion between the ORMU wedge and the inner less mobile Apennine structures. This interpretation is compatible with the hypothesis that seismic swarms are mostly associated with almost pure shear faulting [69] and that recurrent crises occur at sectors of plate boundaries which are mostly characterized by aseismic fault slip [70]-[73]. Swarm activity (associated with the rupture of small-scale asperities of the fault surface) would occur when aseismic creep rate undergoes a transient increase, possibly related to an enhanced plate mobility in the short term [61] [74] [75].

In Figure 14 it is worth noting that in the last 20 years almost all the zones considered have experienced a phase of increased activity, possibly related with some sliding at the related boundary sector. This evidence could imply that each seismicity increase, presumably involving a local decoupling between the mobile wedge (Figure 3) and the surrounding zones, has some influence on the probability of seismic activation in the contiguous boundaries. Then, this kind of process gradually migrates along the borders of the mobile belt, until it produces a little displacement of the whole wedge. The relative seismic quiescence of the UTV fault system during the period considered (Figure 14) could reveal that in such zone the sliding between the ORMU wedge and the inner belt has so far been mostly inhibited, which may have favoured the accumulation of strain and the consequent increase of stress at those faults.

Seismic swarms have also been interpreted as the effect of upward diffusion of pressurized fluids coming from upper mantle degassing (mainly carbon dioxide). This hypothesis is coherent with the fact that in geothermal fields, fluid re-injection and subsequent pore-pressure diffusion may enhance microseimic activity [76]. Furthermore, in some areas, such the West Bohemia/Vogtland (central Europe), both frequent swarms and numerous gas vents are recognized [70] [73]. However, this causal relationships weakens for zones where deep fluid uprising is not so evident or absent at all. For instance, in central Italy many carbon dioxide vents are located in the western side (Latium and Toscana), whereas very few centres are recognized in the eastern side (Abruzzi, Umbria and Marche [77]). Thus, the hypothesis that the enhanced swarm activity observed in the Umbria-Marche Apennines after the 1997-1998 Colfiorito and 2009 L'Aquila earthquakes is related to deep fluid uprising [78] [79] is questionable.

\section{Discussion}

Since the principal aim of this work is recognizing the Apennine zones most prone to next strong earthquakes, 


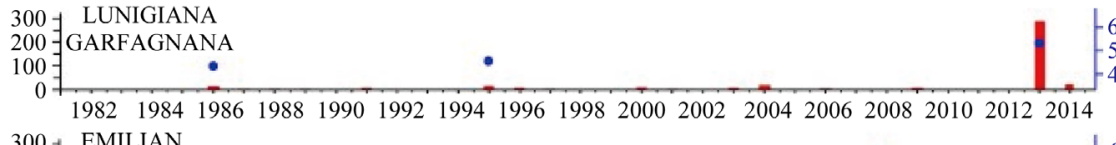
300 - EMILIAN

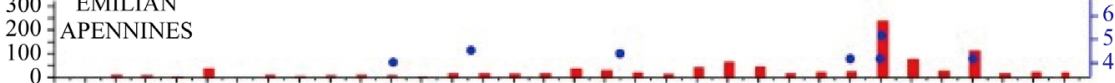

$1982198419861988 \quad 19901992 \quad 1994 \quad 1996 \quad 199820002002 \quad 200420062008201020122014$ 300 J PERRARA

200 BURIED FOLDS•

$100=$

$\begin{array}{lllllllllllllllll}1982 & 1984 & 1986 & 1988 & 1990 & 1992 & 1994 & 1996 & 1998 & 2000 & 2002 & 2004 & 2006 & 2008 & 2010 & 2012 & 2014\end{array}$

$300+$ SILLARO

$200=$

$100=$

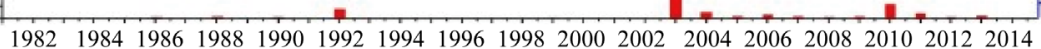
$300-$ ROMAGNA

$200=$ APENINES

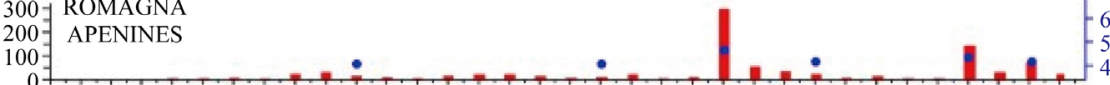

$19821984198619881990199219941996199820002002 \quad 200420062008201020122014$ $300-$ FORLI

200

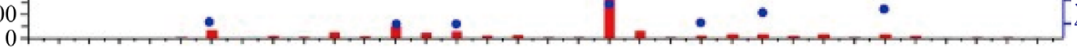

19821984198619881990199219941996199820002002200420062008201020122014 $300-\quad$ UPPER

200 TIBER VALLEY

$100=$

$\begin{array}{llllllllllllllllll}1982 & 1984 & 1986 & 1988 & 1990 & 1992 & 1994 & 1996 & 1998 & 2000 & 2002 & 2004 & 2006 & 2008 & 2010 & 2012 & 2014\end{array}$ $300-$ GUBBIO

$200=$<smiles></smiles>

19821984198619881990199219941996 300 - COLFIORITO

$200=$ NORCIA

$100=$.

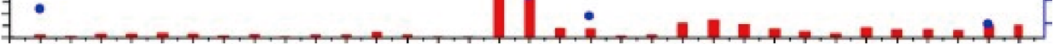

19821984198619881990199219941996199820002002200420062008201020122014

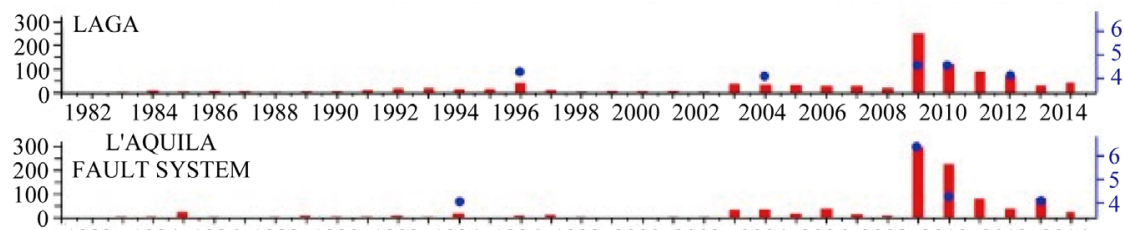

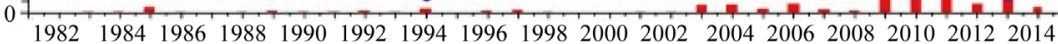

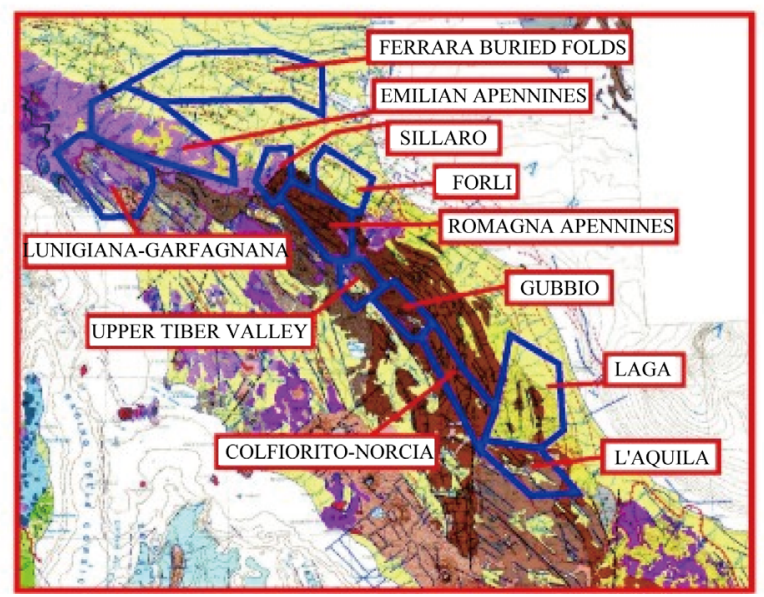

Figure 14. Time patterns of the number of shocks with $M>2$ (red bars) and equivalent magnitude (Me, blue circles) in the various sectors of the Apennine belt since 1981. The values of Me have been computed from the annual seismic energy releases by using the relation given in the caption of Figure 4(b). Seismicity data from [67] [68]. 


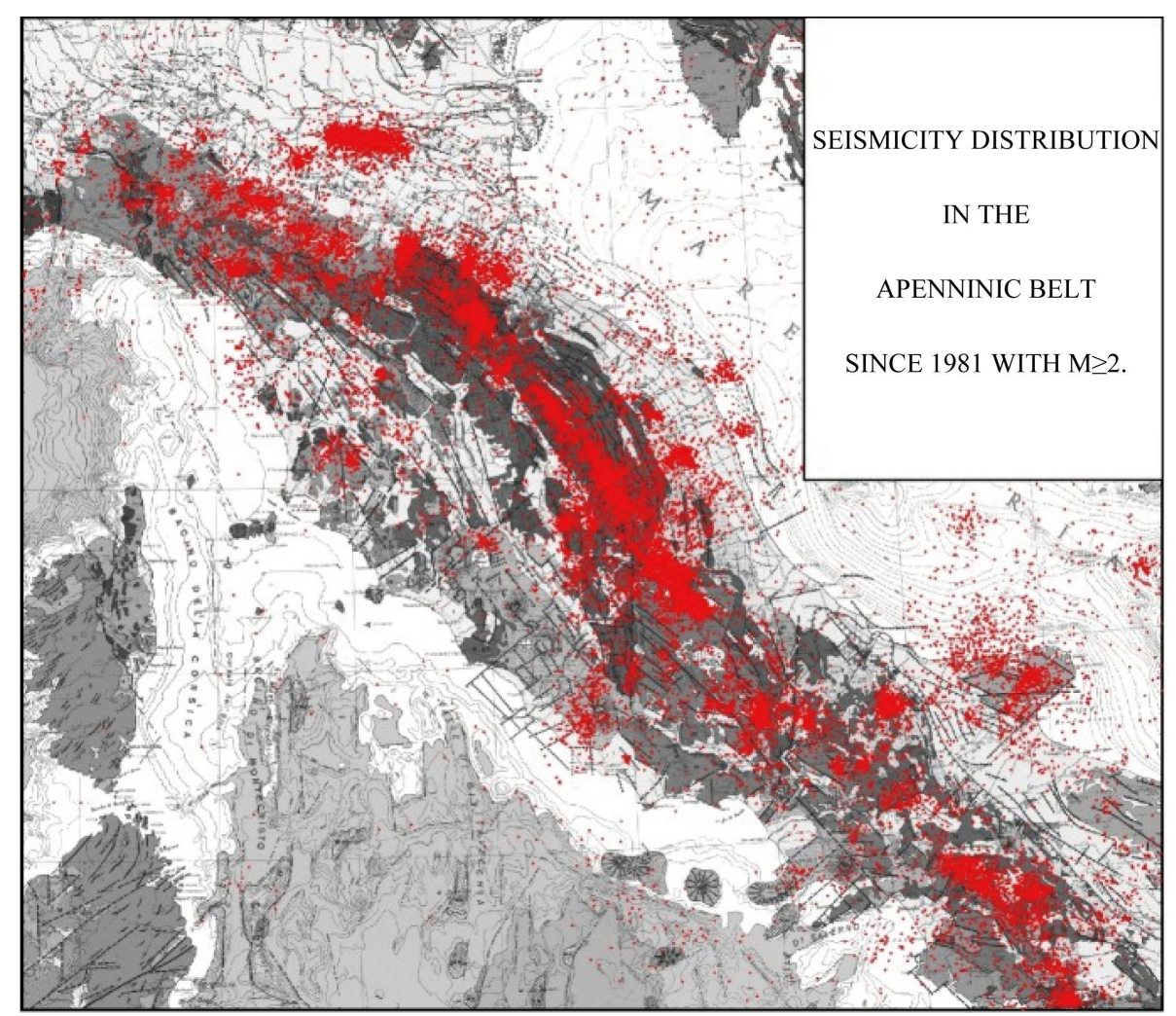

Figure 15. Epicentres of earthquakes with $\mathrm{M}>2$ occurred since 1981. Seismicity data from [67] [68]. See caption of Figure 14.

we now discuss about which constraints can be obtained by taking into account the arguments and evidence described earlier.

Considering what happened in the Apennine belt during the first 4 sequences (Figures 7-10), one could try to predict the most probable prosecution of the ongoing sequence (Figure 11). Above all, it must be taken into account that in the present sequence, the sector of the LA platform that has been mainly mobilized is the Gran Sasso wedge, as indicated by the occurrence of strong shocks at the outer compressional border of that wedge (1933, 1943 and 1950) and its inner transtensional boundary (the L'Aquila fault system, 2009). This implies that the sector of the RMU wedge that is expected to accelerate, in response to the above events, is the ORMU wedge, delimited at West by the No-Cf-GT-Gu-UTV fault system. This hypothesis is compatible with the fact that the southernmost segments of such system (Norcia and Colfiorito) have been already activated by major events (1979 and 1997). After this initial development, one could expect that the zones located around the northern parts of the ORMU wedge are the most prone to next strong earthquakes.

-Among the previous sequences, the one that shows the main similarities with the present one is the third sequence (Figure 9), since it has been characterized by the mobilization of the outer LA sector in the Central Apennines (Gran Sasso wedge) and then by the seismic activation of the zones bordering the southern part of the ORMU wedge (1719-1751, Figure 9(b)). Since the above phase was followed by the occurrence of major shocks along the borders of the northern part of the ORMU wedge (1768-1796, Figure 9(c)), one could tentatively expect that such behaviour will also characterize the continuation of the present sequence. This consideration, along with the major aspects of the GPS velocity field and the possible implications of the spatio-temporal pattern of minor seismicity, led us to believe that the next shocks with $\mathrm{M} \geq 5.0$ will most probably occur at the boundaries of the mobile ORMU wedge. As concerns stronger earthquakes $(M \geq 5.5)$, we believe that the zones most prone to such type of events are the Upper Tiber Valley (UTV) and the Romagna-Forlì (Ro-Fo) fault systems (Figure 16). This conviction is based on the following remarks.

-The UTV lies along the inner boundary of the ORMU wedge, that is presumably affected by the highest strain rate among the various ORMU boundary zones. The relative motion rate between ORMU wedge and the 




Figure 16. The violet dashed line tentatively delineates the boundaries of the ORMU wedge, that in our view correspond to the zones most prone to next shocks with $M \geq 5.0$. The two red boxes identify the Upper Tiber Valley and the Romagna-Forli zones, that are supposed to be the most probable sites of next strong shocks (M $\geq 5.5$ ) in the Northern Apennines.

inner belt, inferred from the GPS velocity field (Figure 4), is about 2 - $3 \mathrm{~mm} / \mathrm{y}$. Since the last major earthquake in the UTV occurred about 100 years ago (1917, $M=5.9)$, the relative displacement accumulated at such fault is about 20 - $30 \mathrm{~cm}$, which may be associated with a earthquake magnitude of about $5.5-6.0$, following the relation proposed by [60].

-It is reasonable to expect that, at the light of numerical experiments carried out for other earthquakes in the Apennine belt [57] [58], the effects of the post-seismic relaxation induced by the 1979 and 1997 major shocks in the Norcia and Colfiorito sources are being most intense at the UTV and Ro-Fo zones.

-It is reasonable to expect that the present acceleration of the ORMU wedge enhances stress at the decoupling Ro-Fo fault system. The probability of major shocks at this last zone may increase after an eventual activation of the UTV faults (and viceversa).

-The UTV and Ro-Fo zones have been the site of several major historical earthquakes (Rovida et al., 2011). This condition also holds for other ORMU boundary sectors, as the Rimini-Ancona and Marche ridge zones, but such zones are presumably undergoing a lower strain rate, due to the slower relative motion between the RMU wedge and the Adria plate (Figure 2).

-The fact that the UTV zone has not undergone any significant increase of seismicity in the last 30 years, in contrast with the almost total seismic activation (with major shocks or swarms) of the other ORMU boundary zones, might indicate that the UVT sector has accumulated an higher elastic strain during that period, with the consequent increase of stress at the related faults.

-The main seismic zones located in the northernmost Apennine sector (TE wedge, mainly the LunigianaGarfagnana zones) have experienced major earthquakes $(1481,1497,1834,1837,1920)$ during the grey, green and yellow sequences of Figure 5, i.e. the ones that were preceded by very strong shocks in the Southern and Central Apennines. Only moderate earthquakes have instead occurred in the TE wedge during the orange sequence, which was not characterized by very strong seismicity in the Central and Southern Apennines. These cases could imply that the seismic activation of the Lunigiana and Garfagnana fault systems requires the occurrence of large decoupling shocks in the southern sectors of the mobile belt. When this condition is not fulfilled, the migrating deformation is not evidently sufficient to induce significant seismicity in the northernmost sector of the TE wedge. The present sequence has so far involved three major earthquakes in the Southern Apennines 
(1930, 1962, 1980) and a number of moderate shocks in the Central Apennines (1933, 1943, 1950, 1984, 2009). However, the fact that such events were separated by relatively long time intervals suggests that their effect in the Northern Apennines may be weaker than the ones that were induced during some of the previous sequences in response to very strong shocks concentrated in time (Figure 5). In fact, it is well known that the brittle behaviour of rocks (i.e. the highest probability of earthquakes) increases as the strain rate increases [61]-[64]. The arguments given in this point suggest that the probability of major earthquakes at the boundaries of the TE wedge are lower than the ones of shocks at the boundaries of the ORMU wedge.

-Once tentatively identified the UTV and Ro-Fo as priority zones in the study area (Figure 16), it is opportune to take into account their previous seismic behaviour (Table 7), in order to gain orientative insights into the seismic potentiality of such fault systems, in terms of maximum macroseismic intensity (Imax, MCS scale) and average recurrence time (Tr), for instance.

Table 7. Earthquakes with I $\geq$ VII occurred in the Upper Tiber Valley and
Romagna-Forlì zones since 1000 A.D. [65]. Events with I $\geq$ IX are evidenced by red.

\begin{tabular}{|c|c|}
\hline Upper Tiber Valley & Romagna-Forli' \\
\hline & 1194 (VII) \\
\hline \multicolumn{2}{|l|}{1269 (VII-VIII) } \\
\hline 1270 (VII-VIII) & 1279 (VII-VIII) \\
\hline \multicolumn{2}{|l|}{1352 (IX) } \\
\hline \multicolumn{2}{|l|}{1353 (IX) } \\
\hline & 1383 (VII-VIII) \\
\hline \multirow[t]{2}{*}{1389 (IX) } & 1393 (VII) \\
\hline & 1428 (VIII) \\
\hline \multicolumn{2}{|l|}{1458 (VIII-IX, VII) } \\
\hline 1484 (VII) & 1483 (VIII-IX) \\
\hline \multicolumn{2}{|l|}{1489 (VII) } \\
\hline & 1509 (VII) \\
\hline \multicolumn{2}{|l|}{1558 (VII-VIII) } \\
\hline \multicolumn{2}{|l|}{1559 (VIII) } \\
\hline & 1584 (IX) \\
\hline & $1661(X)$ \\
\hline 1693 (VII) & 1688 (IX, VII) \\
\hline \multicolumn{2}{|l|}{1694 (VII-VIII) } \\
\hline \multicolumn{2}{|l|}{1731 (VII-VIII) } \\
\hline & 1768 (IX) \\
\hline \multirow[t]{2}{*}{1789 (IX) } & 1781 (IX-X, VIII) \\
\hline & 1813 (VII) \\
\hline \multirow[t]{3}{*}{1865 (VII-VIII) } & 1861 (VII) \\
\hline & 1870 (VIII) \\
\hline & 1881 (VII) \\
\hline \multirow[t]{2}{*}{1897 (VII-VIII) } & 1895 (VII-VIII) \\
\hline & 1911 (VII) \\
\hline 1917 (IX-X) & 1918 (IX) \\
\hline \multirow[t]{2}{*}{1948 (VII) } & 1952 (VII) \\
\hline & 1956 (VII) \\
\hline
\end{tabular}


For the UTV zone, the known seismic history since 1000 [65] provides a value of IX-X for Imax. Tr is 53 years for $\mathrm{I} \geq$ VII, 145 years for for $\mathrm{I} \geq$ VIII and 203 years for $\mathrm{I} \geq$ IX. The last events with $\mathrm{I}=\mathrm{VII}$ and $\mathrm{I}=\mathrm{IX}$ have occurred 67 years ago (1948) and 98 (1917) years ago respectively. The minimum and maximum inter-event time intervals are 1 and 134 years for I $\geq$ VII, respectively, and 1 and 400 years for I $\geq$ IX, respectively.

For the Ro-Fo zone Imax is X, Tr is 44 years for I $\geq$ VII, 113 years for for $\mathrm{I} \geq \mathrm{VIII}$ and 169 years for $\mathrm{I} \geq \mathrm{IX}$. The last events with I = VII and I = IX have occurred 59 years ago (1956) and 97 years ago (1918) respectively. The minimum and maximum inter-event time intervals are 4 and 104 years for I $\geq$ VII, respectively, and 13 and 137 years for I $\geq$ IX, respectively. Of course, one must be aware that the above estimates can be considerably influenced by eventual (likely) incompleteness of the oldest parts of the catalogue.

\section{Conclusions}

The spatio-temporal distribution of major earthquakes $(M \geq 5.5)$ in the periAdriatic zones may closely be connected with the progressive displacement of the Adria plate towards Europe [2] [3]. In the period considered (1400-2014), we have tentatively recognized a number of sequences during which strong seismicity has migrated from the southern zones (Northern Hellenides and Calabrian Arc) to the northern ones (Eastern Southern Alps and Northern Dinarides). Each seismic sequence may have allowed a further step in the northward displacement of Adria.

This work focuses on how major earthquakes have distributed along the Apennine belt during the various periAdriatic sequences, aiming at getting insights into the short-term tectonic mechanisms that control seismicity patterns. The results so far obtained suggest that the starting of each sequence is mainly determined by the occurrence of strong seismicity in the Southern Apennines, which is supposed to decouple the Molise-Sannio wedge from the inner less mobile belt. The consequent acceleration of that wedge enhances belt parallel compression in the eastern sector of the Central Apennines, strengthening shear stress (and earthquake probability) at the major belt parallel faults systems (L'Aquila and Fucino) in that zone. When this context causes the seismic activation of the L'Aquila fault, the sector of the LA platform which accelerates is relatively narrow, mainly involving the Gran Sasso Arc. In that case, the increase of shear stress in the Northern Apennines affects the Norcia-Colfiorito-Gualdo Tadino-Gubbio discontinuity (Figure 3), whose eventual seismic activation favours the acceleration of the ORMU wedge. When, instead, decoupling in the Central Apennines develops by the seismic activation of the Fucino fault system (as occurred in 1915), the acceleration of the wider mobilized LA sector may have major seismic effects in the northern part of the ORMU wedge and around the TE wedge (as occurred in the time interval 1916-1920).

It is argued that the implications of the proposed seismotectonic context are compatible with the spatio-temporal distribution of major shocks in the Apennine belt during the seismic sequences so far identified (Figures 7-12).

The information inferred from this investigation is tentatively used for recognizing where the probability of major earthquakes is now highest in the study area. In particular, it is suggested that the Northern Apennines is the zone most prone to next shocks. Within the above zone, the mobility of the ORMU wedge with respect to the surrounding regions is recognized as the process that can most probably determine the location of the next major earthquakes. In this view, the boundaries of that wedge may be taken as priority zones in the strategy of seismic risk mitigation. Support to the above hypothesis is provided by the fact that recent seismic activity (M > 2 ) in the Apennine belt has concentrated along the tectonic discontinuities that decouple the above wedge from the inner belt (Figure 15). Furthermore, it is pointed out that during the last 30 years almost all boundary sectors of the ORMU wedge have undergone at least one phase of increased activity (Figure 14). The fact that such phenomenon has not affected the Upper Tiber Valley could imply an higher probability of seismic activation, with respect to the other zones. This and other evidence discussed in the text have led us to suggest that the Upper Tiber Valley and the Romagna-Forli zones are the most prone to next strong earthquakes $(M \geq 5.5)$.

No information is provided about the timing of the expected events. Furthermore, one must be aware that the uncertainty that may affect the predictions suggested in this work can hardly be estimated, due to the complexity of the underlying seismotectonic processes. However, in spite of the possible uncertainties, we think that the evidence and arguments here discussed are plausible and that they actually represent the most reliable attempt at recognizing priority seismic zones in the study area, where initiatives for seismic risk mitigation should be encouraged. 


\section{Acknowledgements}

We are grateful to an anonymous Reviewer for his constructive suggestions.

\section{References}

[1] Mantovani, E., Viti, M., Babbucci, D., Cenni, N., Tamburelli, C. and Vannucchi, A. (2012) Middle Term Prediction of Earthquakes in Italy: Some Remarks on Empirical and Deterministic Approaches. Bollettino di Geofisica Teorica ed Applicata, 53, 89-111.

[2] Mantovani, E., Viti, M., Babbucci, D., Tamburelli, C., Cenni, N., Baglione, M. and D’Intinosante, V. (2015) Recognition of Periadriatic Seismic Zones Most Prone to Next Major Earthquakes: Insights from a Deterministic Approach. In: D’Amico, S., Ed., Earthquakes and Their Impact on Society, Springer Natural Hazard Series, Springer, Berlin, in Press.

[3] Viti, M., Mantovani, E., Babbucci, D., Cenni, N. and Tamburelli, C. (2015) Where the Next Strong Earthquake in the Italian Peninsula? Insights by a Deterministic Approach. Bollettino di Geofisica Teorica ed Applicata, 56, in Press.

[4] Mantovani, E., Viti, M., Babbucci, D., Tamburelli, C. and Albarello, D. (2006) Geodynamic Connection between the Indentation of Arabia and the Neogene Tectonics of the Central-Eastern Mediterranean Region. In: Dilek, Y. and Pavlides, S., Eds., Post-Collisional Tectonics and Magmatism in the Mediterranean Region and Asia, Geological Society of America, Boulder, 15-49.

[5] Mantovani, E., Viti, M., Babbucci, D. and Tamburelli, C. (2007) Major Evidence on the Driving Mechanism of the Tyrrhenian-Apennines Trench-Arc-Back Arc System from Crop Seismic Data. Bollettino Della Società Geologica Italiana, 126, 459-471.

[6] Mantovani, E., Viti, M., Babbucci, D. and Albarello, D. (2007) Nubia-Eurasia Kinematics: An Alternative Interpretation from Mediterranean and North Atlantic Evidence. Annals of Geophysics, 50, 311-336.

[7] Mantovani, E., Babbucci, D., Tamburelli, C. and Viti, M. (2009) A Review on the Driving Mechanism of the Tyrrhenian-Apennines System: Implications for the Present Seismotectonic Setting in the Central-Northern Apennines. Tectonophysics, 476, 22-40. http://dx.doi.org/10.1016/j.tecto.2008.10.032

[8] Mantovani, E., Viti, M., Babbucci, D., Tamburelli, C., Cenni, N., Baglione, M. and D’Intinosante, V. (2014) Generation of Back-Arc Basins as Side Effect of Shortening Processes: Examples from the Central Mediterranean. International Journal of Geosciences, 5, 1062-1079. http://dx.doi.org/10.4236/ijg.2014.510091

[9] Viti, M., Mantovani, E., Babbucci, D. and Tamburelli, C. (2006) Quaternary Geodynamics and Deformation Pattern in the Southern Apennines: Implications for Seismic Activity. Bollettino della Società Geologica Italiana, 125, $273-291$.

[10] Viti, M., Mantovani, E., Babbucci, D. and Tamburelli, C. (2009) Generation of Trench Arc-Back Arc Systems in the Western Mediterranean Region Driven by Plate Convergence. Bollettino della Società Geologica Italiana, 128, 89106.

[11] Viti, M., Mantovani, E., Babbucci, D. and Tamburelli, C. (2011) Plate Kinematics and Geodynamics in the Central Mediterranean. Journal of Geodynamics, 51, 190-204. http://dx.doi.org/10.1016/j.jog.2010.02.006

[12] Bott, M.H.P. and Dean, D.S. (1973) Stress Diffusion from Plate Boundaries. Nature, 243, 339-341. http://dx.doi.org/10.1038/243339a0

[13] Anderson, D.L. (1975) Accelerated Plate Tectonics. Science, 167, 1077-1079. http://dx.doi.org/10.1126/science.187.4181.1077

[14] Pollitz, F.F. (2003) The Relationship between the Instantaneous Velocity Field and the Rate of Moment Release in the Lithosphere. Geophysical Journal International, 153, 595-608. http://dx.doi.org/10.1046/j.1365-246X.2003.01924.X

[15] Heki, K. and Mitsui, Y. (2013) Accelerated Pacific Plate Subduction Following Interplate Thrust Earthquakes at the Japan Trench. Earth and Planetary Science Letters, 363, 44-49. http://dx.doi.org/10.1016/j.epsl.2012.12.031

[16] Freed, A.M. (2005) Earthquake Triggering by Static, Dynamic, and Postseismic Stress Transfer. Annual Review of Earth and Planetary Sciences, 33, 335-367. http://dx.doi.org/10.1146/annurev.earth.33.092203.122505

[17] Pollitz, F.F., Burgmann, R. and Banerjee, P. (2006) Postseismic Relaxation Following the Great 2004 Sumatra-Andaman Earthquake on a Compressible Self-Gravitating Earth. Geophysical Journal International, 167, 397-420. http://dx.doi.org/10.1111/j.1365-246X.2006.03018.x

[18] Freed, A.M., Ali, S.T. and Burgmann, R. (2007) Evolution of Stress in Southern California for the Past 200 Years from Coseismic, Postseismic and Interseismic Stress Changes. Geophysical Journal International, 169, 1164-1179. http://dx.doi.org/10.1111/j.1365-246X.2007.03391.x

[19] Ryder, I., Parsons, B.E., Wright, T.J. and Funning G.J. (2007) Post-Seismic Motion Following the 1997 Manyi (Tibet) Earthquake: InSAR Observations and Modelling. Geophysical Journal International, 169, 1009-1027. 
http://dx.doi.org/10.1111/j.1365-246X.2006.03312.x

[20] Ergintav, S., McClusky, S., Hearn, E., Reilinger, R., Cakmak, R., Herring, T., Ozener, H., Lenk, O. and Tari, E. (2009) Seven Years of Postseismic Deformation Following the 1999, $M=7.4$ and $M=7.2$, Izmit-Duzce, Turkey Earthquake Sequence. Journal of Geophysical Research, 114, Article ID: B07403. http://dx.doi.org/10.1029/2008JB006021

[21] Ozawa, S., Nishimura, T., Suito, H., Kobayashi, T., Tobita, M. and Imakiire, T. (2011) Coseismic and Post-Seismic Slip of the 2011 Magnitude-9 Tohoku-Oki Earthquake. Nature, 475, 373-376. http://dx.doi.org/10.1038/nature10227

[22] Mantovani, E., Viti, M., Babbucci, D. and Vannucchi, A. (2008) Long-Term Prediction of Major Earthquakes in the Calabrian Arc. Environmental Semeiotics, 1, 190-207. http://dx.doi.org/10.3383/es.1.2.3

[23] Louvari, E., Kiratzi, A.A., Papazachos, B.C. and Katzidimitriou, P. (2001) Fault-Plane Solutions Determined by Waveform Modelling Confirm Tectonic Collision in the Eastern Adriatic. Pure and Applied Geophysics, 158, 16131637. http://dx.doi.org/10.1007/PL00001236

[24] Benetatos, C. and Kiratzi, A. (2006) Finite-Fault Slip Models for the 15 April 1979 (Mw 7.1) Montenegro Earthquake and Its Strongest Aftershock of 24 May 1979 (Mw 6.2). Tectonophysics, 421, 129-143.

http://dx.doi.org/10.1016/j.tecto.2006.04.009

[25] Aliaj, S. (2006) The Albanian Orogen: Convergence Zone between Eurasia and the Adria Microplate. In: Pinter, N., Grenerczy, G., Weber, J., Stein, S. and Medak, D., Eds., The Adria Microplate: GPS Geodesy, Tectonics and Hazard. Springer, Dordrecht, 133-149. http://dx.doi.org/10.1007/1-4020-4235-3_09

[26] Kokkalas, S., Xypolias, P., Koukouvelas, I. and Doutsos, T. (2006) Postcollisional Contractional and Extensional Deformation in the Aegean Region. In: Dilek, Y. and Pavlides, S., Eds., Post Collisional Tectonics and Magmatism in the Mediterranean Region and Asia, Special Paper 409, Geological Society of America, Boulder, 97-123.

[27] Louvari, E., Kiratzi, A.A. and Papazachos, B.C. (1999) The Cephalonia Transform Fault and Its Extension to Western Lefkada Island (Greece). Tectonophysics, 308, 223-236. http://dx.doi.org/10.1016/S0040-1951(99)00078-5

[28] Markusic, S. and Herak, M. (1999) Seismic Zoning of Croatia. Natural Hazards, 18, 269-285. http://dx.doi.org/10.1023/A:1026484815539

[29] Kuk, V., Prelogovic, E. and Dragicevic, I. (2000) Seismotectonically Active Zones in the Dinarides. Geologia Croatica, 53, 295-303.

[30] Poljak, M., Zivcic, M. and Zupancic, P. (2000) The Seismotectonic Characteristics of Slovenia. Pure and Applied Geophysics, 157, 37-55. http://dx.doi.org/10.1007/PL00001099

[31] Burrato, P., Poli, M.E., Vannoli, P., Zanferrari, A., Basili, R. and Galadini, F. (2008) Sources of Mw5+ Earthquakes in Northeastern Italy and Western Slovenia: An Updated View Based on Geological and Seismological Evidence. Tectonophysics, 453, 157-176. http://dx.doi.org/10.1016/j.tecto.2007.07.009

[32] Bressan, G., Bragato, P. and Venturini, C. (2003) Stress and Strain Tensors Based on Focal Mechanisms in the Seismotectonic Framework of the Eastern Southern Alps. Bulletin of the Seismological Society of America, 93, 1280-1297. http://dx.doi.org/10.1785/0120020058

[33] Galadini, F., Poli, M.E. and Zanferrari, A. (2005) Seismogenic Sources Potentially Responsible for Earthquakes with M $\geq 6$ in the Eastern Southern Alps (Thiene-Udine Sector, NE Italy). Geophysical Journal International, 161, 739-762. http://dx.doi.org/10.1111/j.1365-246X.2005.02571.x

[34] Cenni, N., Mantovani, E., Baldi, P. and Viti, M. (2012) Present Kinematics of Central and Northern Italy from Continuous GPS Measurements. Journal of Geodynamics, 58, 62-72. http://dx.doi.org/10.1016/j.jog.2012.02.004

[35] Cenni, N., Viti, M., Baldi, P., Mantovani, E., Bacchetti, M. and Vannucchi, A. (2013) Present Vertical Movements in Central and Northern Italy from GPS Data: Possible Role of Natural and Anthropogenic Causes. Journal of Geodynamics, 71, 74-85. http://dx.doi.org/10.1016/j.jog.2013.07.004

[36] Cenni, N., Viti, M. and Mantovani, E. (2015) Space Geodetic Data (GPS) and Earthquake Forecasting: Examples from the Italian Geodetic Network. Bollettino di Geofisica Teorica ed Applicata, 56, in Press.

[37] Altamimi, Z., Métivier, L. and Collilieux, X. (2012) ITRF2008 Plate Motion Model. Journal of Geophysical Research, 117, Article ID: B07402. http://dx.doi.org/10.1029/2011JB008930

[38] Piccardi, L., Tondi, G. and Cello, G. (2006) Geo-Structural Evidence for Active Oblique Extension in South-Central Italy. In: Pinter, N., et al., Eds., The Adria Microplate: GPS Geodesy, Tectonics and Hazard, Springer Verlag, Berlin, 95-108. http://dx.doi.org/10.1007/1-4020-4235-3_07

[39] Scisciani, V. and Calamita, F. (2009) Active Intraplate Deformation within Adria: Examples from the Adriatic Region. Tectonophysics, 476, 57-72. http://dx.doi.org/10.1016/j.tecto.2008.10.030

[40] Finetti, I.R., Boccaletti, M., Bonini, M., Del Ben, A., Pipan, M., Prizzon, A. and Sani, F. (2005) Lithospheric Tectono-Stratigraphic Setting of the Ligurian Sea-Northern Apennines-Adriatic Foreland from Integrated CROP Seismic Data. In: Finetti, I.R., Ed., CROP Project: Deep Seismic Exploration of the Central Mediterranean and Italy, Elsevier, 
Amsterdam, 119-158.

[41] Mirabella, F., Barchi, M., Lupattelli, A., Stucchi, E. and Ciaccio, M.G. (2008) Insights on the Seismogenic Layer Thickness from the Upper Crust Structure of the Umbria-Marche Apennines (Central Italy). Tectonics, 27, Article ID: TC1010. http://dx.doi.org/10.1029/2007TC002134

[42] Ascione, A., Cinque, A., Improta, L. and Villani, F. (2003) Late Quaternary Faulting within the Southern Apennines Seismic Belt: New Data from Mt. Marzano Area (Southern Italy). Quaternary International, 101-102, $27-41$. http://dx.doi.org/10.1016/S1040-6182(02)00127-1

[43] Ascione, A., Caiazzo, C. and Cinque, A. (2007) Recent Faulting in Southern Apennines (Italy): Geomorphic Evidence, Spatial Distribution and Implications for Rates of Activity. The Italian Journal of Geosciences, 126, 293-305.

[44] Cello, G., Mazzoli, S., Tondi, E. and Turco, E. (1997) Active Tectonics in the Central Apennines and Possible Implications for Seismic Hazard Analysis in Peninsular Italy. Tectonophysics, 272, 43-68. http://dx.doi.org/10.1016/S0040-1951(96)00275-2

[45] Cello, G., Mazzoli, S. and Tondi, E. (1998) The Crustal Fault Structure Responsible for the 1703 Earthquake Sequence of Central Italy. Journal of Geodynamics, 26, 443-460. http://dx.doi.org/10.1016/S0264-3707(97)00051-3

[46] Amoruso, A., Crescentini, L. and Scarpa, R. (1998) Inversion of Source Parameters from Near- and Far Field Observations: An Application to the 1915 Fucino Earthquake, Central Apennines, Italy. Journal of Geophysical Research, 103, 29989-29999. http://dx.doi.org/10.1029/98JB02849

[47] Piccardi, L., Gaudemer, Y., Tapponnier, P. and Boccaletti, M. (1999) Active Oblique Extension in the Central Apennines (Italy): Evidence from the Fucino Region. Geophysical Journal International, 139, 499-530. http://dx.doi.org/10.1046/j.1365-246x.1999.00955.x

[48] Boncio, P. and Lavecchia, G. (2000) A Structural Model for Active Extension in Central Italy. Journal of Geodynamics, 29, 233-244. http://dx.doi.org/10.1016/S0264-3707(99)00050-2

[49] Brozzetti, F., Boncio, P., Lavecchia, G. and Pace, B. (2009) Present Activity and Seismogenetic Potential of a Low-Angle Normal Fault System (Città Di Castello, Italy): Constraints from Surface Geology, Seismic Reflection Data and Seismicity. Tectonophysics, 463, 31-46. http://dx.doi.org/10.1016/j.tecto.2008.09.023

[50] Catalano, S., Monaco, C. and Tortorici, L. (2004) Neogene-Quaternary Tectonic Evolution of the Southern Apennines. Tectonics, 23, Article ID: TC2003. http://dx.doi.org/10.1029/2003TC001512

[51] Ferranti, L., Santoro, E., Gazzella, M.E., Monaco, C. and Morelli, D. (2009) Active Transpression in the Northern Calabria Apennines, Southern Italy. Tectonophysics, 476, 226-251. http://dx.doi.org/10.1016/j.tecto.2008.11.010

[52] Caputo, R., Salviulo, L. and Bianca, M. (2008) Late Quaternary Activity of the Scorciabuoi Fault (Southern Italy) as Inferred from Morphotectonic Investigations and Numerical Modeling. Tectonics, 27, Article ID: TC3004. http://dx.doi.org/10.1029/2007TC002203

[53] Finetti, I. and Del Ben, A. (1986) Geophysical Study of the Tyrrhenian Opening. Bollettino di Geofisica Teorica ed Applicata, 110, 75-156.

[54] Finetti, I.R. and Del Ben, A. (2005) Ionian Tethys Lithosphere Roll-Back Sinking and Back-Arc Tyrrhenian Opening From New CROP Seismic Data. In: Finetti, I.R., Ed., CROP Project: Deep Seismic Exploration of the Central Mediterranean and Italy, Elsevier, Amsterdam, 483-504.

[55] Del Ben, A., Barnaba, C. and Taboga, A. (2008) Strike-Slip Systems as the Main Tectonic Features in the Plio-Quarternary Kinematics of the Calabrian Arc. Marine Geophysical Researches, 29, 1-12. http://dx.doi.org/10.1007/s11001-007-9041-6

[56] Viti, M., D’Onza, F., Mantovani, E., Albarello, D. and Cenni, N. (2003) Post-Seismic Relaxation and Earthquake Triggering in the Southern Adriatic Region. Geophysical Journal International, 153, 645-657. http://dx.doi.org/10.1046/j.1365-246X.2003.01939.x

[57] Viti, M., Mantovani, E., Cenni, N. and Vannucchi, A. (2012) Post-Seismic Relaxation: An Example of Earthquake Triggering in the Apennine Belt (1915-1920). Journal of Geodynamics, 61, 57-67. http://dx.doi.org/10.1016/j.jog.2012.07.002

[58] Viti, M., Mantovani, E., Cenni, N. and Vannucchi, A. (2013) Interaction of Seismic Sources in the Apennine Belt. Physics and Chemistry of the Earth, 63, 25-35. http://dx.doi.org/10.1016/j.pce.2013.03.005

[59] Mantovani, E., Viti, M., Babbucci, D., Albarello, D., Cenni, N. and Vannucchi, A. (2010) Long-Term Earthquake Triggering in the Southern and Northern Apennines. Journal of Seismology, 14, 53-65. http://dx.doi.org/10.1007/s10950-008-9141-z

[60] Wells, D.L. and Coppersmith, K.J. (1994) New Empirical Relationships among Magnitude, Rupture Length, Rupture Width, Rupture Area and Surface Displacement. The Bulletin of the Seismological Society of America, 84, 974-1002.

[61] Toda, S., Stein, R.S. and Sagiya, T. (2002) Evidence from the AD 2000 Izu Islands Earthquake Swarm that Stressing 
Rate Governs Seismicity. Nature, 419, 58-61. http://dx.doi.org/10.1038/nature00997

[62] Kato, A., Ohnaka, M., Yoshida, S. and Mochizuki, H. (2003) Effect of Strain Rate on Constitutive Properties for the Shear Failure of Intact Granite in Seismogenic Environments. Geophysical Research Letters, 30, 2108. http://dx.doi.org/10.1029/2003GL018372

[63] Niemeijer, A.R. and Spiers, C.J. (2007) A Microphysical Model for Strong Velocity Weakening in PhyllosilicateBearing Fault Gouges. Journal of Geophysical Research, 112, Article ID: B10405. http://dx.doi.org/10.1029/2007JB005008

[64] Savage, H.M. and Marone, C. (2007) Effects of Shear Velocity Oscillations on Stick-Slip Behavior in Laboratory Experiments. Journal of Geophysical Research, 112, Article ID: B02301. http://dx.doi.org/10.1029/2005JB004238

[65] Rovida, A., Camassi, R., Gasperini, P. and Stucchi, M., Eds. (2011) CPTI11, the 2011 Version of the Parametric Catalogue of Italian Earthquakes. INGV, Bologna.

[66] Guidoboni, E. and Comastri, A. (2005) Catalogue of Earthquakes and Tsunamis in the Mediterranean Area from the 11th to the 15th Century. INGV-SGA, Roma-Bologna, $1037 \mathrm{p}$.

[67] Castello, B., Selvaggi, G., Chiarabba, C. and Amato, A. (2006) CSI Catalogo Della Sismicità Italiana 1981-2002. Versione 1.1, INGV-CNT, Roma. http://csi.rm.ingv.it/

[68] ISIDe Working Group (2010) Italian Seismological Instrumental and Parametric Database. http://iside.rm.ingv.it

[69] Ibs-von Seht, M., Plenefisch, T. and Klinge, K. (2008) Earthquake Swarms in Continental Rifts—A Comparison of Selected Cases in America, Africa and Europe. Tectonophysics, 452, 66-77. http://dx.doi.org/10.1016/j.tecto.2008.02.008

[70] Horálek, J. and Fischer, T. (2008) Role of Crustal Fluids in Triggering the West Bohemia/Vogtland Earthquake Swarms: Just What We Know (A Review). Studia Geophysica et Geodaetica, 52, 455-478. http://dx.doi.org/10.1007/s11200-008-0032-0

[71] Roland, E. and McGuire, J.J. (2009) Earthquake Swarms on Transform Faults. Geophysical Journal International, 178, 1677-1690. http://dx.doi.org/10.1111/j.1365-246X.2009.04214.x

[72] Thomas, A.M., Bürgmann, R. and Dreger, D.S. (2013) Incipient Faulting near Lake Pillsbury, California, and the Role of Accessory Faults in Plate Boundary Evolution. Geology, 41, 1119-1122.

[73] Fischer, T., Horálek, J., Hrubcová, P., Vavryčuk, V., Bräuer, K. and Kämpf, H. (2014) Intra-Continental Earthquake Swarms in West-Bohemia and Vogtland: A Review. Tectonophysics, 611, 1-27. http://dx.doi.org/10.1016/j.tecto.2013.11.001

[74] Kundu, B., Legrand, D., Gahalaut, K., Gahalaut, V.K., Mahesh, P., Kamesh Raju, K.A., Catherine, J.K., Ambikapthy, A. and Chadha, R.K. (2012) The 2005 Volcano-Tectonic Earthquake Swarm in the Andaman Sea: Triggered by the 2004 Great Sumatra-Andaman Earthquake. Tectonics, 31, Article ID: TC5009. http://dx.doi.org/10.1029/2012TC003138

[75] Lienkaemper, J.J., McFarland, F.S., Simpson, R.W., Bilham, R.G., Ponce, D.A., Boatwright, J.J. and Caskey, J.S. (2012) Long-Term Creep Rates on the Hayward Fault: Evidence for Controls on the Size and Frequency of Large Earthquakes. Bulletin of the Seismological Society of America, 102, 31-41. http://dx.doi.org/10.1785/0120110033

[76] Shapiro, S.A., Huenges, E. and Borm, G. (1997) Estimating the Crust Permeability from Fluid Injection-Induced Seismic Emission at the KTB Site. Geophysical Journal International, 131, F15-F18. http://dx.doi.org/10.1111/j.1365-246X.1997.tb01215.x

[77] Minissale, A. (2004) Origin, Transport and Discharge of $\mathrm{CO}_{2}$ in Central Italy. Earth-Science Reviews, 66, 89-141. http://dx.doi.org/10.1016/j.earscirev.2003.09.001

[78] Lombardi, A.M., Marzocchi, W. and Cocco, M. (2010) On the Increase of Background Seismicity Rate during the 1997-1998 Umbria-Marche, Central Italy, Sequence: Apparent Variation or Fluid-Driven Triggering? Bulletin of the Seismological Society of America, 100, 1138-1152. http://dx.doi.org/10.1785/0120090077

[79] Chiarabba, C., De Gori, P. and Mele, F.M. (2015) Recent Seismicity of Italy: Active Tectonics of the Central Mediterranean Region and Seismicity Rate Changes after the Mw 6.3 L’Aquila Earthquake. Tectonophysics, 638, 82-93. 